DOHERTY, JEANNE L., M.S. Associations among Diet, Inflammation and Iron Status in Young Adults (2019)

Directed by Dr. Seth Armah 69 pp

Obesity is a risk factor for poor iron status due to the chronic, low-grade inflammation of adipose tissue hypertrophy. Among other positive acute phase proteins, the hepatic peptide hormone hepcidin is secreted during inflammation, inhibiting systemic iron efflux from enterocytes and downregulating systemic iron recycling by suppressing iron release from the mononuclear phagocyte system. Conversely, production and secretion of the iron transport protein transferrin by the liver is reduced during inflammation. In addition to increasing adiposity, certain foods are also known to promote inflammatory states and may contribute to these same effects in concert with, or independent of obesity. In this study, we evaluated how inflammatory diets are related to inflammatory and iron status biomarkers among 98 young adults with normal weight, overweight and obesity. Three-day dietary records and biomarker data for iron status and inflammation from two cross-sectional studies of similar design (Diet and Inflammation Study, $n=39$ and the Selenium and Inflammation Study, $n=59$ ) were used in this study. Dietary Inflammatory Index (DII) scores were calculated for each subject using nutrients and other dietary components from the dietary records, and subjects were further classified into two DII categories using cluster analysis. Using ANOVA we compared iron status and inflammatory markers among subjects with normal weight, overweight and obesity. We determined the association between DII scores or DII category and Creactive protein (CRP), hepcidin, serum iron and total iron binding capacity (TIBC). Statistical significance was set at $\mathrm{P} \leq 0.05$. Mean $\pm \mathrm{SEM}$ were reported for continuous 
variables except for skewed variables in which case geometric means (geometric mean \pm 1 SEM interval) were reported. CRP concentration differed significantly by BMI category ( $\mathrm{p}<0.05$ for all comparisons) and serum iron (SI) was lower in the obese category compared to normal weight $(\mathrm{p}=0.014)$. Results from the regression analysis showed that high DII scores were associated with increased CRP concentration and decreasing TIBC. Similarly, subjects in the anti-inflammatory diet group showed higher TIBC compared to those in the inflammatory diet group. In conclusion, our study showed that inflammatory diets may impair iron status by reducing the capacity of the iron transport protein transferrin to transport iron in the blood. 


\title{
ASSOCIATIONS AMONG DIET, INFLAMMATION AND IRON STATUS IN
}

\section{YOUNG ADULTS}

\author{
by
}

Jeanne L Doherty

\author{
A Thesis Submitted to \\ the Faculty of The Graduate School at \\ The University of North Carolina at Greensboro \\ in Partial Fulfillment \\ of the Requirements for the Degree \\ Master of Science
}

Greensboro

2019

Approved by

Committee Chair 
(C) 2019 Jeanne L Doherty 
I dedicate this thesis to the spirit of Pro Humanitate so that the health, well-being and vitality of others may be improved, and the risk for diet driven chronic diseases will be reduced. 


\section{APPROVAL PAGE}

This thesis written by JEANNE L DOHERTY has been approved by the following committee of the Faculty of The Graduate School at The University of North Carolina at Greensboro

Committee Chair Committee Members

Date of Acceptance by Committee

$\overline{\text { Date of Final Oral Examination }}$ 


\section{ACKNOWLEDGEMENTS}

Foremost I would like to thank my faculty mentor Seth Armah for giving me the opportunity to work as a graduate assistant on his Diet and Inflammation Study. I learned so much about conducting research with human subjects and I am very grateful for his patience and unwavering support. Dr. Armah's knowledge, attention to detail and statistical prowess were invaluable to this thesis project.

I would also like to thank Lauren Haldeman and Steven Fordahl for serving on my thesis committee. Dr. Fordahl's wisdom and guidance kept me motivated throughout the project. I am especially grateful for Dr. Haldeman who was the first to encourage me to earn a Master of Science degree in Nutrition. Her leadership will always inspire me.

Additionally, I am thankful for my early science professors Bruce Banks, $\mathrm{PhD}$ and Maulik Trivedi, $\mathrm{PhD}$ for dispelling my fears of chemistry through their inspiring and fascinating lectures and for every instructor in the Nutrition department for the expertise and knowledge they share daily. I would also like to recognize the ongoing support of Paula Cooney, the departmental research coordinator, and Sherry Ritter, the department's administrative assistant who makes everything possible in the Department of Nutrition.

Lastly, I would like to express my deepest appreciation for my husband, Timothy and children, Jack and Katy, my parents and my sister for encouraging me in every way while I pursued learning about food and nutrition. Their love, care and support are truly boundless. 
TABLE OF CONTENTS

Page

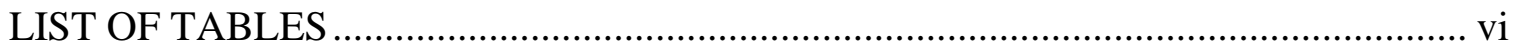

LIST OF FIGURES ……………………………............................................... vii

\section{CHAPTER}

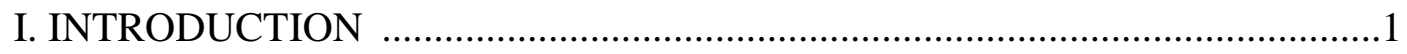

II. LITERATURE REVIEW ……………………….................................

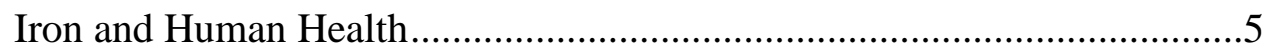

Factors Affecting Iron Status ………………………............................

Foods and Inflammation .....................................................................15

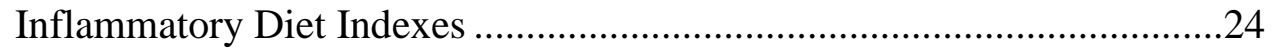

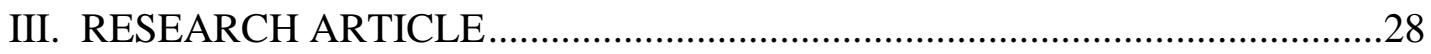

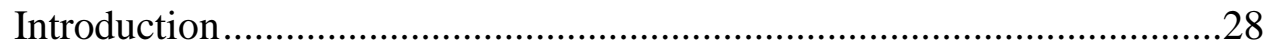

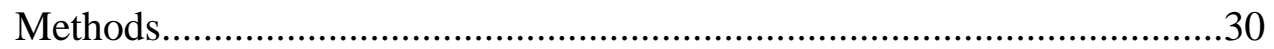

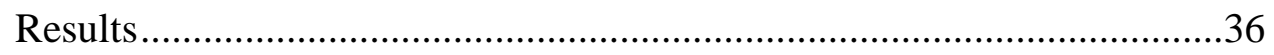

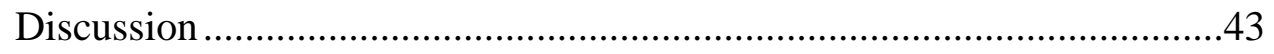

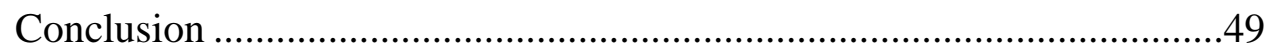

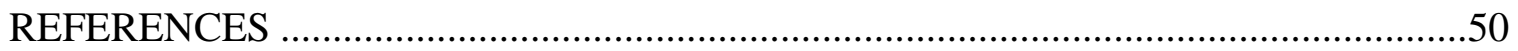




\section{LIST OF TABLES}

Page

Table 1. Food Components of DII Scoring Algorithm ..............................................34

Table 2. Background Characteristics According to BMI.............................................36

Table 3. Selected Nutrient Intakes and DII Scores According to BMI ............................38

Table 4. Inflammatory and Iron Status Biomarkers According to BMI ..........................39

Table 5. Associations of DII Scores with CRP and Hepcidin .....................................40

Table 6. Associations of DII Category with CRP and Hepcidin ................................41

Table 7. Associations of DII Scores with Iron Status Biomarkers ................................42

Table 8. Associations of DII Category with Iron Status Biomarkers ..........................43 


\section{LIST OF FIGURES}

Page

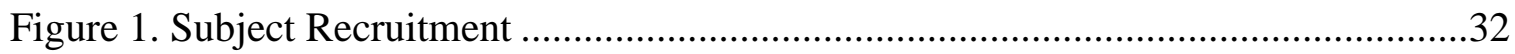




\section{CHAPTER I}

\section{INTRODUCTION}

Beyond providing nutrients, certain foods offer other health benefits through unique properties such as their antioxidant and their anti-inflammatory properties. The effects of foods and their components on inflammation have been investigated in both observational and experimental studies (1-4). In conjunction with epigenetic research, an understanding of how exposure to certain foods influences genetic expression and post translational modification of proteins is becoming well established (5-10). The upregulation of inflammatory cytokines by food components is an important concept that continues to be widely studied as the mechanism by which phenotypic changes toward a chronic disease phenotype are born.

Inflammatory cytokines are small proteins that play a primary role in local and systemic signaling that initiate the immune response to infection and injury. Namely, an increase in interleukin 6 (IL-6), interleukin one beta (IL-1 $)$, and tumor necrosis factor alpha $(\mathrm{TNF} \alpha)$ are associated with an increase in the hepatic protein, C-Reactive protein (CRP) which binds to the surface of the affected cells to augment various immunological processes of the innate immune system $(11,12)$. In addition to stimulating release of CRP, the hepatic peptide hormone, hepcidin is also released and its job is to keep a tight homeostatic regulation of iron. Circulating hepcidin causes sequestration of circulating 
iron into the liver and macrophages, reduces iron absorption in the intestines and decreases iron efflux from enterocytes into the bloodstream.

During the acute phase response, the immune system resolves pathophysiological threats and normal iron physiology can be restored. However, individuals who are overweight or obese have been found to have chronically elevated levels of hepcidin and other markers of inflammation even in the absence of infection or injury resulting in poor iron status (13-19). It is suspected that the increases in hepcidin and other inflammatory markers in the overweight and obese may be attributed to an accumulation of activated macrophages in adipose tissue that secrete adipocytokines including IL-6, and TNF $\alpha$ which activates transcription of the iron storage protein ferritin (20,21). Atypical adaptations to iron metabolism during obesity related chronic inflammatory states are thus being observed and current studies suggest that obesity may be a risk factor for poor iron status $(13-15,22,23)$.

Coupled with activated macrophage initiation of IL-6, dietary sources can also stimulate IL-6 production and begin the inflammatory cascade (24-26). Food related mechanisms that have been implicated in the promotion of the inflammatory phenotype center around increased expression of the protein complex, nuclear factor kappa-lightchain-enhancer of activated B cells $(\mathrm{NF} \kappa \mathrm{B})$ which is responsible for producing IL-6 $(27,28)$. For example, certain free fatty acids in the diet that act as non-immune ligands to activate toll-like receptor 4 (TLR4) have been shown to decrease the expression of peroxisome proliferator-activated receptor-gamma coactivator 1 (PGC1) which will 
upregulate the expression of $\mathrm{NF \kappa B}(29)$. Other dietary sources of inflammation are the advanced glycation end products of highly processed foods which have been found to increase oxidative stress and overexpression of the Receptor for Advanced Glycation End Products (RAGE) in enterocytes $(30,31)$. These may all contribute to sustaining chronic inflammation and impairing iron status.

However, individuals who regularly consume dietary antioxidants and antiinflammatory dietary components such as omega 3 fatty acids and certain flavonoids may demonstrate improved biomarkers of inflammation, reducing their future risk of chronic disease (32-34). Proposed mechanisms of action for anti-inflammatory effects of bioactive food components include improved composition of cell membranes, support during oxidative stress and through cell signaling pathways that can alter gene expression (35-37). Although the exact mechanisms are still being actively investigated, qualitative studies and data from experiments in cell and animal models offer convincing evidence on the health benefits of including anti-inflammatory foods regularly in the diet (38-44).

In order to most effectively evaluate the contribution of diet to inflammation, various dietary patterns and indexes have been developed. Among them is the Dietary Inflammatory Index (DII) which was designed to consider both proinflammatory and anti-inflammatory foods (45). The DII is a validated predictive model for inflammatory markers and can be used with a variety of dietary assessment tools including $24 \mathrm{~h}$ recalls, food frequency questionnaires, and dietary records. In observational studies, higher DII 
scores have been associated with higher IL-6 and higher CRP concentrations. However, no study has investigated its relationship with hepcidin and iron status.

Main objective: The aim of this study was to determine the association between dietary intake and inflammation and how that influences circulating iron biomarkers in young adults. Circulating iron was assessed using serum iron and total iron binding capacity (TIBC).

Specific Objectives

1. To compare circulating iron (serum iron and TIBC) and inflammatory biomarkers among study participants with normal weight, overweight and obesity.

Hypothesis: Subjects with higher BMI will have poorer circulating iron status biomarkers and higher CRP concentration

2. To determine the association between the DII score and inflammation among study participants.

Hypothesis: DII scores will be positively associated with CRP concentration among study participants.

3. To determine the association between the DII score and circulating iron biomarkers among study participants Hypothesis: Higher DII scores will be associated with poorer circulating iron biomarkers (serum iron and TIBC). 


\section{CHAPTER II}

\section{LITERATURE REVIEW}

The prevailing obesity epidemic in developed countries and that which is emerging in developing countries due to nutrition transition is alarming. While obesity is a well-known risk factor for various chronic diseases, recent studies have implicated obesity as a risk factor for poor micronutrient status (46). Particularly for iron, low-grade, chronic inflammation associated with obesity may increase concentrations of the iron regulatory protein hepcidin which may negatively influence levels of circulating and functional iron (47). Considering that diet may play a role in reducing inflammation, there is a need to investigate how dietary changes may indirectly influence iron status through its effect on inflammation among individuals with overweight and obesity. This review focuses on the importance of iron to human health, factors that influence iron status and the relationships between diet and inflammation, and methods for assessing the inflammatory effects of foods.

\section{Iron and Human Health}

Iron is required for sustaining human life and in maintaining healthful physiological functions. Iron participates as a catalyst and promoter in enzymes and is a component of several globular proteins such as hemoglobin and myoglobin. Primarily the human body uses iron for the transport of oxygen by red blood cells and thus, a 
majority of body iron is contained in the heme protein, hemoglobin. After hemoglobin ferritin, which stores iron as Fe2, accounts for the next largest supply of the body's iron and is followed by myoglobin, with transferrin containing the least amount of iron, as ferric iron, $(\mathrm{Fe} 3)(48)$. In addition to the globin proteins, heme is a part of peroxidases and redox cytochrome enzymes. Iron functions in ribonucleotide reductase and is a part of several iron sulfur proteins including aconitase of the TCA cycle and nucleotide binding protein (49). In general, proper iron homeostasis is required for cognition, immunity and physical performance.

\section{Cognitive Development and Functioning}

Progress in iron research continues to support and further clarify how iron is a key factor for proper cognitive development and functioning, effective immunological responses, and sustaining physical competencies. A novel study comparing the effects of iron deficiency (ID) on both white and gray matter in developing rats supports that even mild iron deficiencies may affect hypomyelination in hippocampal and cortical tissues. Greminger et al. observed proximal shifts in apical dendrite branching and significant decreases in basal dendrite length and branching with $50 \%$ fewer interactions in the Fe deplete diet group compared to the Fe diet group (50). In a prospective cohort

study using cord blood, Amin et al. compared the auditory brainstem evoked response of infants born full term. Results of the study showed significantly prolonged interpeak latencies in the infants whose cord blood serum ferritin levels were between 11-75 ng/ml compared to infants with cord blood serum ferritin over $75 \mu \mathrm{g} / \mathrm{ml}(51)$. There is an 
increasing pace of studies on the associations of iron status and attention deficit disorders, pointing to the effects of iron deficiency (ID) on frontal lobe functioning(52). A study of women of reproductive age adds support to previous findings that even marginal declines in iron status of non-anemic women are correlated with reduced proficiency in completing executive functioning tasks such as sustained attention, learning and shifting, inhibitory control, working memory and problem solving (53). Results of this study are the first to suggest that even marginal increments in ferritin and total body iron are related to improvements in problem solving and planning tasks among non-anemic iron deficient women of reproductive age.

Immunity

Current research on the relationship between iron status and immunological response includes studies on asthma and lung function, improved immune function studies, and how iron deficiency may be protective against malaria (54-58). Using data from the 2007-2010 survey cycles of the National Health and Nutrition Examination Survey (NHANES), Brigham et al. found that among women 20-49 years of age, those with the highest ferritin values experienced an average reduced risk of lifetime asthma, and current asthma by $31 \%$ and $53 \%$ respectively (55). In addition to ferritin, the iron binding glycoprotein lactoferrin (LF) which is very similar in structure to transferrin, is another important iron-bound molecule that supports immunity (56). LF is expressed by epithelial tissue and can be taken in exogenously from human breast milk and other unpasteurized, raw mammalian milk sources. Its positive effect on immunity has been 
shown in a number of in vivo and in vitro studies (54). The ability of LF to effect improvements in immune functioning in older adults was observed in an RCT of people ages $66-87$ receiving lactoferrin supplementation. The experimental group in the study experienced significant increases in neutrophil phagocytic capacity, natural killer cell cytotoxicity and limited improvement in lymphocyte subset ratios (57).

Interventions with iron supplementation have also shown improvements in immune functioning. In a case control study on the effects of iron deficiency on the humoral and cell mediated immunity of children, lower CD4 lymphocyte levels as well as impaired CD4:CD8 ratios were improved following 3 months of iron supplementation $(6 \mathrm{mg} / \mathrm{kg} /$ day elemental iron) preceded by treatment for parasitic infections (59). However, supplementing with iron in cases of unresolved parasitic infections has been shown to negatively affect outcomes $(58,60)$.

\section{Optimizing Physical Performance and Aerobic Capacity}

Optimal physical functioning and aerobic capacity are also known to rely on adequate functional iron supplies. While this is a well-established principle, current areas of research are expanding the breadth of the literature to include non-anemic iron deficiencies, effects of intense physical training on individuals with iron deficiencies, and the benefits of iron supplementation on aerobic and strength training performance among women, including athletes, women in the military and recreationally active women (6165). Together these studies offer good evidence for monitoring and for iron 
supplementation in men and women who may have non-anemic iron deficiencies or who engage in moderate to high intensity activities on a regular basis.

\section{Factors Affecting Iron Status}

\section{Iron Intake and Absorption}

Although the majority of body iron supplies are maintained by recycling during erythropoiesis, enough iron must be taken in by the diet to replenish the 1-2 mg lost daily (49). Recommended daily intakes for iron are $8 \mathrm{mg}$ for adult men, $18 \mathrm{mg}$ for adult women and $27 \mathrm{mg}$ for pregnant and lactating women (66), however Armah et al. have suggested that these values may need to be adjusted upwards to be able to meet physiological iron requirements (67). Humans acquire iron through consumption of heme from myoglobin or hemoglobin in meats and inorganic iron of plant foods, synthetically fortified foods or of animal tissues. While a higher percentage of iron is absorbed from heme sources (68), most of the dietary iron consumed is from iron fortified cereals and breads due to the widespread consumption of both food products (69).

It is well known that iron from heme sources is taken up and utilized more efficiently than non-heme sources. This is based primarily on the consensus that heme moves into the enterocytes of the brush border membrane (BBM) intact, unencumbered by competition for transporters or through loss due to "anti-nutrient" activity of oxalates and phytates. Evidence continues to support this assertion and points to endocytosis or movement through the transmembrane protein heme carrier protein (HCP1) as probable 
modes of absorption at the BBM (70,71). A study of piglets with iron deficiency anemia (IDA) showed a four-fold increased expression of Slc46a1, the gene coding for HCP1 in piglets given oral supplementation of bovine hemoglobin compared to both control piglets given parenteral $\mathrm{Fe}$ and to piglets receiving intramuscular injections of the conventional treatment of iron dextran. Results also showed that piglets receiving oral heme supplementation had more than a three-fold increase in Fpn mRNA expression on the basolateral membrane (BLM) of duodenal enterocytes compared to both control and to iron dextran injected piglets. Furthermore, hepcidin mRNA expression in the livers and plasma of the heme and control piglets remained consistently low throughout the study compared to increased hepcidin levels in iron dextran injected pigs, which began to increase significantly at day fourteen of the study and continued to do so until the study's conclusion (72).

Following digestion, iron from vegetable sources is transferred into the cellular environment from the intestinal lumen by a divalent metal transporter (DMT1). Control of iron absorption by enterocytes depends both on systemic factors, local transcription of HIF-2a, and by posttranscriptional mechanisms of the iron regulatory protein and iron response element systems (71). Since ferric iron (Fe3) must be reduced prior to transport by DMT1, its absorption can be increased by the presence of ascorbic acid which reduces it to ferrous iron (Fe2), allowing it to bypass the ferric reductase enzyme, duodenal cytochrome b (Dcytb) present in the lumen. Other dietary components that enhance nonheme iron absorption are amino acids, animal proteins and fermented products. 
Alternatively, other digested compounds such as phytates and oxalates may bind with iron in the lumen causing it to pass unabsorbed and unutilized by the body. Similarly, other metals, like calcium, cadmium, cobalt, magnesium and zinc in excess, may compete with iron for DMT1, reducing the amount of iron absorbed and cause it to pass unutilized by the body $(73,74)$. Recent ex vivo experiments have demonstrated that hepcidin too can reduce absorption of dietary iron by downregulating mRNA levels of DMT1 and Dcytb (75).

Because vegetarians do not include heme or animal protein in the diet, it is estimated that only between $5 \%$ and $12 \%$ of iron in their diet is absorbed (76). For this reason, the United States Institute of Medicine recommends that vegetarians consume 1.8 times more iron compared to those consuming a mixed Western diet (66). Proper meal planning that accommodates optimal iron absorption via nutrient to nutrient interactions are essential for maintaining proper iron status. Researchers Ghatpande et al. (77) studied the relationship between iron status, inflammation and the dietary data of 85 adolescent girls in India, a nation whose population relies heavily on non-heme iron from plant-based diets. Among the subjects, 28\% were anemic and 66\% were ID. Their primary goal was to examine the relationship between ferritin, serum iron, hepcidin, $\mathrm{TNF} \alpha$ and B12. Overall the study reported that regular consumption of vitamin $\mathrm{C}$ rich fruits had significant effects on iron status and that B12 was negatively associated with TNF $\alpha$. Amla, a fruit very rich in vitamin C, was regularly included in the diets of girls with higher serum iron, and a significant positive correlation between hepcidin and 
ferritin was observed. Among the girls who ate guava regularly, B12 and ferritin associations were significant. An interesting finding involved consumption of fetid cassia, (fruits from a tree that grows in ruined buildings) which is a traditional treatment for ringworm. Subjects who did not eat fetid cassia were at a 3.9 times increased risk of low serum iron.

Additionally, sufficient intake of B12 either from supplements or fish sources must also be made available for effective erythropoiesis to protect against anemia. The benefits of a combined folic acid (FA), B12 and iron supplementation were shown in a supervised RCT among 446 IDA adolescent girls living in a very low socioeconomic section of New Delhi. In the study, Bensal et al. (78) showed that while both the FA and B12 +FA iron supplements reduced the prevalence of iron deficiency anemia (IDA) among the group, the B12 + FA iron supplement reduced IDA among the subjects more significantly as well as improved ferritin status compared to the FA+iron supplement.

\section{Physiological Needs}

The higher incidences of ID and IDA among pregnant women, premenopausal women, and children reflect the increased physiological demands for iron in these demographics (79-81). Pregnant women require more dietary iron for increases in blood volume and supplies to the fetus, premenopausal women with menorrhagia need more iron for replacing excessive blood losses and children require more iron for the changes in blood volume and hemoglobin concentrations (66). Also, hypoxia is a physiological state that cause changes to iron status. Subsequently, in these individuals, upregulation of 
erythropoietin will enhance intestinal iron absorption and dietary iron intake will subsequently have a greater impact on iron status than in individuals without higher physiological needs (82).

High altitudes, severe blood loss, low erythrocyte production and adipose tissue hypoxia will limit oxygen supplies for red blood cell production. When these changes are sensed by baroreceptors in nephrons, EPO transcription is upregulated in the in peritubular fibroblasts in the renal cortex via binding of hypoxia inducible factor (HIF) heterodimers to hypoxia responsive element (HRE) of the EPO gene (83). The increases in EPO suppresses hepcidin via upregulation of the erythroid, erythroferrone (ERFE) and ultimately causes increases in dietary absorption to correct the deficiency $(84,85)$.

\section{Infection}

Intestinal parasites are another gastrointestinal disorder that can impair iron status. While most common in developing nations and among children, intestinal parasites continue to be a major cause of anemia globally. Parasitic infestations on their own, or in combination with an already poor diet quality can worsen iron status. An increased prevalence of the intestinal parasite Giardia, a major cause of diarrhea (86), is suspected of increasing IDA, especially among school children in both developed and developing countries (87). Hussein et al. (87) conducted an analysis of 650 stool samples from pre-school Egyptian children presenting with IDA to determine the association of Giardia infection types with IDA. While several intestinal parasites were discovered, 88 of the children were shown as having only giardiasis. Their results showed that Giardia 
assemblages A were associated with $90.9 \%$ of the IDA cases and Giardia assemblage B with only $9.1 \%$ of the cases. Helicobacter pylori (H. pylori) which is also found in populations around the world is more prevalent in older people with recent studies showing that H.pylori may be impacting vitamin B12 status in addition to reduced blood iron $(88,89)$. A case control study of younger hospitalized patients hospitalized with H.pylori showed that the decreases in B12 and iron levels were improved to near normal levels upon treatment for the infection (90). Lastly, studies on the effects of colonic microbiota are demonstrating a viable link between an organism's microbiome and expression of hepcidin (91).

\section{Inflammation}

Hepcidin, an antimicrobial peptide produced mainly by the liver, helps to maintain safe supplies of functional iron by facilitating the sequestration of circulating iron into storage as ferritin if liver iron stores are high or whenever inflammation is triggered by the innate immune system. This inflammation cascade is initiated at the site of infection or injury by neutrophils which secrete interleukin-1 (IL-1) to recruit macrophages that in turn secrete interleukin-6 (IL-6) that signals the liver to produce and release hepcidin $(92,93)$. As hepcidin circulates in the body, it prevents iron from entering the bloodstream by binding to and disabling the transmembrane iron exporter protein, ferroportin (Fpn) which is found primarily on hepatocytes, macrophages and enterocytes. While this effectively limits the efflux of iron from these cells and into circulation, hepcidin's role in decreasing absorption in the duodenum is not as well 
established. However, in a recent ex vivo study, it is reported that hepcidin exposure elicited changes in human duodenal mucosa that modulate several steps of the iron absorption process, including a reduction of dietary iron by Dcytb, its uptake by enterocytes through DMT1, the mucosal uptake of heme iron by HCP1, and enterocyte iron release to plasma by Fpn1 in conjunction with hephaestin through transcriptional change (89). Conversely, when iron is required for the formation of red blood cells, erythroferrone (ERFE) is produced and hepcidin is suppressed (94). The impact of inflammation on iron status is seen in conditions such as autoimmune disorders, and inflammatory bowel disease in which high hepcidin concentration may predispose patients to anemia of inflammation (12).

\section{Foods and Inflammation}

It is well recognized that foods can significantly impact inflammatory status through a variety of mechanisms. Some examples of foods and food components that have been linked to inflammation are discussed below.

Fatty Acids

Certain fatty acids have been shown to directly influence proinflammatory cytokines via the arachidonic pathway and polyphenols have been shown to indirectly affect inflammation by reducing conversion of arachidonic acid to eicosanoids, modulating nitric oxide production (NOS) and downregulating the expression of genes associated with inflammatory signaling pathways, scavenging of reactive oxygen species (ROS) and other free radicals of metabolic reactions, and chelating metal ions (26,95- 
98). Both monounsaturated fatty acids (MUFA) and polyunsaturated fatty acids (PUFA)s are known to be healthful fats and are recommended over saturated fats which have been shown to have acute inflammatory effects (95-98).

The potential health benefits of MUFAs and PUFAs were highlighted in the largescale intervention study, PREDIMED, which studied how three diets containing different fat profiles affected the risk for CVD among high risk patients. An extra virgin olive oil (EVOO; MUFA diet) diet, a PUFA rich diet with nuts (walnuts, almonds and hazelnuts), and a low-fat diet fashioned by the American Heart Association recommendations, were studied. All three diets included recommendations for high consumption of fruits and vegetables. A number of sub studies have emerged comparing these three different diets with plasma concentrations of inflammatory cytokines in the blood samples.

Casas et al. (38) investigated the anti-inflammatory effects of MUFA and PUFA diets in a subcohort of 164 PREDIMED participants with atherosclerosis over the course of 12 months. C-reactive protein and IL- 6 were reduced by $45 \%$ and $35 \%$ and $95 \%$ and $90 \%$ in the MUFA and PUFA diet respectively $(\mathrm{P}<0.05)$. In a long-term study of an elderly cohort, the same researchers found that at 3 and 5-year test points, both the MUFA and PUFA rich diet showed a significant reduction of IL-6, IL-8, MCP-1, and MIP-1 $(\mathrm{P}<0.05)$ compared to subjects following the low-fat diet recommendations. The MUFA rich diet stood out further in that it demonstrated improvements in TNF- $\alpha$, as well as the other markers of CVD disease risk studied $(\mathrm{P}<0.05)$. 
The Canola Oil Multisite Intervention Trial (COMIT) compared the effects of three different Canola oils and two safflower blended oils on the biomarkers of CVD risk which included CRP and IL-6. The Canola oils were designed to have higher percentages of omega-3 fatty acids while containing the same amount of protein, carbohydrate, lipid, saturated fat, fiber and cholesterol percentages whereas the safflower blended oil diets contained higher omega 6 fatty acids than the Canola oils. A primary objective of the study was to better identify the effects of oils containing various amounts of alpha linolenic acid (ALA). Linoleic acid (LA) Oleic acid (OA) and docosahexaenoic acid DHA outside of the Mediterranean diet context (99). Since only endpoint differences were reported it is unknown how CRP levels changed from baseline among the subjects. However, endpoint data showed that CRP was significantly lower in the Canola oil diet compared to the corn/safflower blend control diet which had a disproportionately higher omega 6 to omega 3 ratio.

Another interventional study that included a comparison of the anti-inflammatory effects of an unprocessed oil with a processed oil demonstrated the anti-inflammatory benefits of EVOO compared to refined olive oil (ROO). In the study, HIV patients who consumed an EVOO diet had significantly lower average CRP levels compared to those patients consuming ROO diet, which contained no polyphenols (100). These observations were attributed to the presence of polyphenols in reducing the effects of lipid oxidation, thereby protecting the tissues (epithelia) from oxidative stress and injury which elicits and inflammatory response. 


\section{Polyphenols}

Polyphenols are a group of plant-based chemicals that have at least one phenol group. They are divided into two main groups, phenolic acids of red fruits, black radishes, onions, coffees, cereals and spices and the spectrum of flavonoids, which are found in soy (isoflavones), in berries (anthocyanidins), in herbs (flavones), in broccoli, kale and tea (flavonols), flavanones found in citrus fruits and juices (flavanones). Cell studies, mouse studies and human studies all demonstrate the anti-inflammatory effect of a polyphenol rich diet (PPD) $(101,102)$.

Examples of commonly consumed polyphenol rich foods include coffee and tea. Both beverages contain an array of polyphenols. Chlorogenic acid, 5-caffeoylquinic acid (5-CQA), which is contained in the coffee bean, is consequently one of the most commonly consumed phenolic acids in the world. Green tea is high in flavon-3-ols and black tea which is fermented, also contains oligimeric flavonoids. Both coffee and tea contain the flavonol, quercitin (103). A number of cell culture, animal and human studies have been performed and demonstrate the anti-inflammatory effects of their bioactive components (103-114). Studies have also shown anti-inflammatory benefits of isoflavones which are primarily consumed in beans (115-122) (116-123).

\section{Influences of Western Style Diets}

In contrast to the anti-inflammatory effects of monounsaturated fatty acids and polyphenols found in more traditional diets, injurious metabolic and bioactive byproducts of modern and western style diets are being shown to contribute to the inflammatory 
response both acutely and in chronic fashion. These diets are characterized by being highly caloric, highly processed and high in manufactured, refined oils (123). Recently, Christ et al. (124) demonstrated how exposure to a Western diet both induces the systemic inflammatory response and evokes long term phenotypic changes of an enhanced immune response in myeloid cells regardless of dietary change. This research has revealed the nucleotide-binding oligomerization domain receptor protein 3 (NLRP3) inflammasome as the central mediator of diet induced systemic inflammation and how myeloid precursor reprogramming are involved in the long-term immunomodulatory effects of inflammatory diets. Both are important additions to the established body of research that describes more acute inflammatory responses (125-129) to components of food and may lead to a broader understanding of how food borne "sterile" inflammation may impose a persisting, heightened trained-immune response of metabolic pathways.

\section{Added Sugars}

The added sugars in Western diets include fructose, sucrose, and high fructose corn syrup. Ample evidence supports a role for added sugars in the promotion of chronic disease. (130-134) including a number of studies showing associations between biomarkers of inflammation and increased consumption of sugar sweetened beverages (SSB) (135-138).

In a cross-sectional observational study of 9678 participants in the populationbased Fenland Study, O’Connor et al. (135) studied how free sugars from beverages, fruit juices and processed foods were associated with metabolic risk factors compared to 
sugars from solids with naturally occurring sugars. The results of the analyses revealed that intakes of free sugars from liquids and from sugars added to liquids like coffee and tea but not sugars from foods, were significantly associated with increased CRP among subjects in the highest quintile compared to the lowest quintile of consumption (124).

In a mouse study, seven months of either $15 \%$ glucose or $15 \%$ fructose showed higher accumulations of triglycerides in gastrocnemius muscle of both groups compared to standard chow controls but higher intramyocellular lipids and associated IL-6 in fructose group compared to glucose group (139). More recently, Kovacevic et al. (140), studied female Wistar rats fed either standard chow with water $(n=9)$ or standard chow with $10 \%$ fructose solution for $9 \mathrm{w}$. Results showed NFK- $\beta$ to be higher in the cytosols and nucleosols of VAT of fructose treated rats compared to water with chow treated rats and increased mRNA levels of both NFK- $\beta$ and Il-1B by $25 \%$ and $40 \%$ respectively among fructose treated rats. Together these findings reveal how added sugars induce inflammatory signaling and cytokine production by way of increased oxidative stress in female rats.

A two-week crossover RCT by Raatz et al. (141), examined the metabolic effects of chronic intakes of three sources of sugars (honey, sucrose and high fructose corn syrup) in both glucose tolerant (GT) and glucose intolerant (IGT) subjects $(n=60)$. While triglyceride concentrations were significantly increased in all subjects from baseline, only IGT subjects had significant associations of CRP and glycemic response with the added sugars. Since all three sweeteners had undergone thermal 
processing similar results found in exposures to the different sweeteners may indicate that the heat treatment of the sugars may have caused these effects. Also, the treatment period of only two weeks, along with the relatively low amount $(50 \mathrm{~g})$ of sweetener may not have been enough added sugar to evoke a metabolic inflammatory effect in normoglycemic individuals. Concentrations of CRP observed in the GT group were within the normal range $(<3.0 \mathrm{mg} / \mathrm{L})$. Higher body weight among the IGT group may have been the factor behind the status $\times$ treatment interaction found in the study results $(P=0.03)$.

The inflammatory effects of low to moderate intakes of SSB were first demonstrated by Aeberli et al.(142), in a clinical trial evaluating the effects of beverages containing different sweeteners on metabolic factors in healthy young men. In the study, six different SSB interventions of varying concentrations of fructose, glucose or sucrose were given to normal weight males $(n=29)$ aged $19-25 y$ that did not take regular medications or consume more than $60 \mathrm{~g} \mathrm{SSB}$ daily. Although differences were observed among the sugars on LDL size, all the sugars had a similar effect of increased fasting glucose and more than twice the CRP concentrations compared to baseline. However, a similar RCT in Hispanic adolescents with NAFLD that were exposed to either glucose or fructose beverages, reported that CRP was reduced by nearly half in glucose beverage group compared to fructose after 4 weeks of exposure (143). 


\section{Dietary Advanced Glycation End Products}

In addition to being high in added sugars, western style diets are also high in advanced glycation end products that result from the non-enzymatic Maillard reaction, a common food preparation and processing technique that is widely used in the manufacturing of ultra-processed convenience foods that accommodate modern lifestyles. Dietary advanced glycation end products (dAGEs) are produced when carbonyl groups of non-reducing sugars interact with free amino acid groups of proteins. Intermediate aldehydes and dicarbonyls are first produced and then react with other biomolecules, to form a group of heterogeneous, "end product" compounds (144). Even as much as the cooking process enhances the flavor, aroma, and appearance of foods, these end products which are found to a great degree in French fries, potato chips, baked goods and pasteurized dairy are now believed to contribute to the inflammation associated with chronic and autoimmune diseases $(89,145-147)$. The most commonly studied dAGEs include carboxylethyl-L-lysine (CEL), carboxymethyl-L-lysine (CML), and hydro-methyl-imidazolon (MG-H1). Several observational studies have reported associations between dAGES with increased inflammation and human interventions have demonstrated that reduced inflammatory markers are associated with dAGEs restricted diets $(27,148-151)$.

Researchers Di Pino et al., have conducted both observational and interventional studies investigating the health risks of dAGE exposures in subjects with type 2 diabetes mellitus (T2DM). In their 24w, RCT study, subjects on low dAGE diets had significant 
reductions in CRP compared to standard dAGE diets (150). In their cross-sectional study $(n=85)$, the researchers reported that subjects consuming diets containing more than 15,000 kU/dAGEs/day had significantly higher CRP than subjects whose diets were below 15,000 kU (149). Similar associations between dAGE consumption and serum AGEs (sAGEs) were found by Uribarri et al., (27) in an earlier prospective cohort study of subjects with obesity and risk for metabolic syndrome (MS).

While human studies are still limited, numerous animal models offer insights into dAGEs role in inflammation. The pro-inflammatory effects of CML, and associated renal damage were reported in a study of intrauterine growth retardation piglets $(I U G R)(n=8)$ that were fed either low heated $(\mathrm{LHF})$ or high heated infant formulas (HHF). In the study, Elmhiri et al. (152), observed that piglets receiving HHF had higher mRNA expression and protein activation of NF- $\mathbf{\text { B }}$ by $33 \%$ and $120 \%$ respectively. Recently, a mouse model expressing firefly luciferase under control of NFK-B regulation was used to investigate systemic activation of the secondary messenger pathway, NF- $\mathbf{k B}$ from AGE modified foods. In their experiments, NFк-B luciferase activity was significantly higher in animals fed AGE treated bovine serum albumin (BSA) compared to both BSA fed animals and to positive controls with the highest luciferase activity found in the gut at $6-8 \mathrm{~h}$ post feedings (153).

Increased intakes of dAGEs add to the pool of endogenous AGEs which are produced when proteins such as albumin or globulins react non-enzymatically with plasma glucose. Both dAGEs and endogenous AGEs contribute to an accumulation in 
systemic AGEs which is commonly observed in diabetes, during aging and from diets high in added sugars (148). Circulating AGEs from either source (endogenous or diet derived) can be bound by the advanced glycation end receptor 1 (AGER1) or by the receptor for advanced glycation end products (RAGE). AGER1 binding of AGEs reduces their intracellular and extracellular presence and therefore reduces oxidative stress both intracellularly and among the tissues. RAGE binding of AGEs however, activates several signaling pathways including $\mathrm{NF}-\kappa \mathrm{B}$, resulting in a proinflammatory effect which mediates increases in both transmembrane and soluble RAGE which is found in the sera (14). Most importantly the link between RAGE and the NLRP3 inflammasome was established by Yeh et al., (154) in BALBc mice experiments, who demonstrated that dAGEs mediate activation of NLRP3 secretion of Il $\beta-1$ via conversion of pro-caspase to caspase.

\section{Inflammatory Diet Indexes}

Approaches that reflect the overall health potential of the diet are currently being used to describe population and individual diet patterns. Mediterranean Diet Patterns, Anti-Inflammatory Patterns and the USDA promoted, Healthy US Dietary Pattern are considered more useful in promoting healthful eating, capturing multiple dietary factors, and offering more comprehensive assessments of diet quality while accounting for the complex interactions of foods and nutrients. Researchers have also developed indexes that can be used to assess the inflammatory/anti-inflammatory potential of diets. The Empirical Dietary Inflammatory Index Pattern (EDIP) and a Dietary Inflammatory Index 
(DII) are two examples of such indexes. Both tools were created to quantify the overall effects of the inflammatory foods in an individual's diet in mediating inflammation related diseases and can be used by researchers, public policy makers and clinicians helping patients reduce risk of inflammation related diseases.

\section{Empirical Dietary Inflammatory Pattern Index}

The development of the EDIP was driven by the hypothesis that reduced rank regression analysis (RRR) of dietary data from the Nurses' Health Study (NHS) would be predictive of inflammatory markers (155). The developers believed that an "a posteriori" statistical method would better portray the inflammatory effect of foods by using the response variables to derive the dietary patterns than would an indexed or an "a priori" pattern in which scores are derived from current scientific knowledge. Additionally, the EDII was construct validated in two independent samples of women and men in the NHS. Instead of including single nutrients in inflammatory scoring methodology, the EDII score is based on 39 food groups previously defined in the 1986 and 1990 FFQs of the NHS. First, a mean daily intake of the food groups was calculated and then RRR was applied to derive a dietary pattern associated with CRP, IL-6 and TNF $\alpha$ R2. The researchers found 18 food groups as significantly contributing to the inflammatory markers. Intakes of white meat fish, tomatoes, processed meats, high and low energy beverages, vegetables (other than green leafy or yellow), red meat, refined grains and organ meats were positively associated with inflammatory markers. Curiously, pizza, and snacks which contain refined grains, processed meats and non-leafy vegetables as 
well as fruit juices which are high energy beverages, were inversely associated with inflammatory markers. The relative validity of the EDIP score was evaluated in 2 independent cohorts of health professionals: the Nurses' Health Study (NHS)-II and Health Professionals Follow-up Study (HPFS) (156). Using data from the Women's Health Initiative (WHI) baseline FFQ, researchers confirmed the association of the EDIP score with markers of inflammation in a more racially diverse population of older women. While this tool may be useful in studies that rely on these same food groups and that do not have access to nutrient data analysis, it seems limited in its scope to accurately portray the inflammatory load in diets other than US diets.

\section{The Dietary Inflammatory Index}

The DII also quantifies the overall effects of the inflammatory foods in the diet. Originally, the index was developed from 929 research studies and validated in 2009 with subjects' data from the Seasonal Variation of Blood Cholesterol Study (SEASONS) (45). The DII was developed further by the Cancer Prevention and Control Program at the University of South Carolina in 2011-2012. The researchers enhanced the scoring algorithm of the original DII with the data of more recent and a much larger number $(1,943)$ of articles. In addition to increasing the robustness of the data collected, the scoring system was improved to include differential inflammatory effects reported among various foods and is standardized based on human consumption. Data from eleven regional populations are also factored into the scoring to provide comparison consumption within the food parameters. Thus, the tool is more global and inter- 
regionally reliable. Lastly, the DII can be used with a variety of dietary data. Scoring is reported as a percentile of maximum inflammatory effects of the data from each of the 45 food parameters which include macronutrients, micronutrients, flavonoids, and some herbs.

Since its redesign in 2012 the DII has been used to assess the inflammatory effect of foods in several studies, especially among populations afflicted with colon cancer (125). It has proven to be predictive of gastric and breast cancers, cardiovascular disease CVD, and poor diets (157-162). Its methodology was construct validated with data from NHANES, the SEASONS study and the WHI (163-166). It has also been validated among African Americans (167), post-menopausal women(166), and police officers(168). Recently the same researchers developed a children's DII (C-DII). Up until now, no study has investigated the interrelationships among DII scores inflammation and iron status. 


\section{CHAPTER III RESEARCH ARTICLE}

\section{Introduction}

Poor iron status in obesity is reflected by an iron profile of which hypoferremia is often, but not always paired with hyperferritinemia (22,169-172). These effects, which have been observed in iron studies among subjects with obesity are believed to be the result of increased hepcidin signaling. The hepatocyte response in obesity mirrors that which is seen during the acute phase response in which IL-6 signaling from tissues causes increased hepcidin release from the liver $(93,160,173-176)$. However, in obesity and other chronic inflammatory diseases, the factors fueling the hepatic response remain uncorrected, obstructing hepcidin's original purpose, and subsequently healthy iron metabolism becomes impaired.

It is well established that the relationship between inflammation and obesity is rooted in a mechanism of persisting adipose plasticity that promotes an inflammatory cascade via increased IL-6 signaling. Several studies have described parallel cytokine messaging from both hypertrophic adipocytes and neighboring hypoxic tissues supporting adipocytokine and cytokine release and increased macrophage infiltration into omental fat depots $(174,177,178)$. Overproduction of TNF- $\alpha$, IL-1, IL-6, and MCP-1 results from upregulated hypoxia inducible factor (HIF-1a) in nearby tissues and from toll 
like receptor-4 (TLR-4) due to the lipotoxic effects of chronically elevated free fatty acids (FFAs) in obesity. Together these create a positive feedback paracrine loop of deregulated TNF- $\alpha$ synthesis that promotes and supports persistent systemic inflammation.

Similarly, dietary sources can also stimulate IL-6 production via the immune system and therefore may also contribute to poor iron status by supporting increased release of hepcidin via the inflammatory cascade $(124,125,179,180)$. Food components, such as free fatty acids, added sugars and advanced glycation end products act as nonimmunity mediated ligands for TLR-4, NLRP-3 and other cell surface receptors that mediate induction of nuclear factor kappa B (NFкB). Conversely, diets high in foods with antioxidant and anti-inflammatory properties including polyphenols, vitamin $\mathrm{C}$ and Omega 3 fatty acids for example have been associated with reduced risk of chronic inflammation $(42,44,77)$. Thus, studying associations between diet mediated inflammation and iron status may offer insight into modifying the inflammatory cascade via food intake strategies.

In order to optimally assess the overall effect of dietary inflammation, the dietary inflammatory index (DII) was designed to consider both proinflammatory and antiinflammatory foods. As a validated predictor of IL-6, and the well-known biomarker of systemic inflammation, CRP among a number of populations, the DII may be calculated using a variety of dietary assessment tools including $24 \mathrm{~h}$ recalls, food frequency questionnaires and dietary records. In this study, we sought to investigate if 
inflammatory diets impair iron status independent of BMI. We hypothesized that DII scores will be positively associated with CRP concentration, and that higher DII scores will be associated with poorer circulating iron biomarkers.

\section{Methods}

\section{Study Population}

Data from two cross-sectional studies of the same design namely the Diet and Inflammation Study (DI study) and the Selenium and Inflammation Study (SI study) were used for this analysis(181,182). The DI study was conducted in Spring 2017 to investigate the relationships among diet, hepcidin and iron status. Subjects recruited for this study were those within the age range of 18 to 49 years who were non-pregnant, nonlactating, and non-smoking. Additionally, they were not to have donated blood in the past two months, must not be taking vitamin and mineral supplements, and must have a BMI within the range of 25.0 to $40 \mathrm{~kg} / \mathrm{m}^{2}$. A total of 147 subjects responded to the mass email and 67 subjects were came for screening. Twenty-two participants were ineligible due to BMI, two were excluded due to supplements or medications, and two did not complete blood draw. In total, 39 participants completed the DI study. Dietary intake, and anthropometric (height and weight) measurements were conducted on each subject. Fasting venous blood samples were collected to measure concentrations of iron status and inflammatory markers. The SI study on the other hand was conducted in Spring 2018 to investigate the associations among selenium status, hepcidin concentration and iron status biomarkers in individuals with overweight or obesity compared to normal weight 
controls. Similar to the DI study, subjects were included if they were non-pregnant, nonlactating, non-smoking, not using vitamin and mineral supplements and had not donated blood in the past two months. However, the BMI criteria for inclusion in the SI study was $\geq 18.5 \mathrm{~kg} / \mathrm{m}^{2}$. In addition to collecting dietary, anthropometric and biochemical markers, the SI study also collected additional anthropometric variables such as body fat, visceral fat, and muscle mass, and also measured plasma selenium concentration, and other biomarkers of selenium status among subjects. A total of 129 subjects responded to mass e-mail and 66 came for screening in the SI study of which two opted out for personal reasons, one did not meet BMI criteria, and one subject did not complete the blood draw. In total, 59 subjects were included in that study. Both studies were conducted at the Cemala Foundation Human Nutrition Research Laboratories at the Nutrition Department of The University of North Carolina at Greensboro (UNCG). The study protocols were approved by the Institutional Review Board of UNCG. Summary of subject recruitment and inclusion in the two studies is shown in Figure 1. In each of the studies, informed written consent was obtained at screening from every subject before recruitment. After signing the consent form, each participant was requested to complete a screening form requiring information such as demography, vitamin and mineral supplement use, medical history and pregnancy status. Height and weight measurements were also done at screening to assess BMI for inclusion. 
Figure 1. Subject Recruitment

Diet and Inflammation study

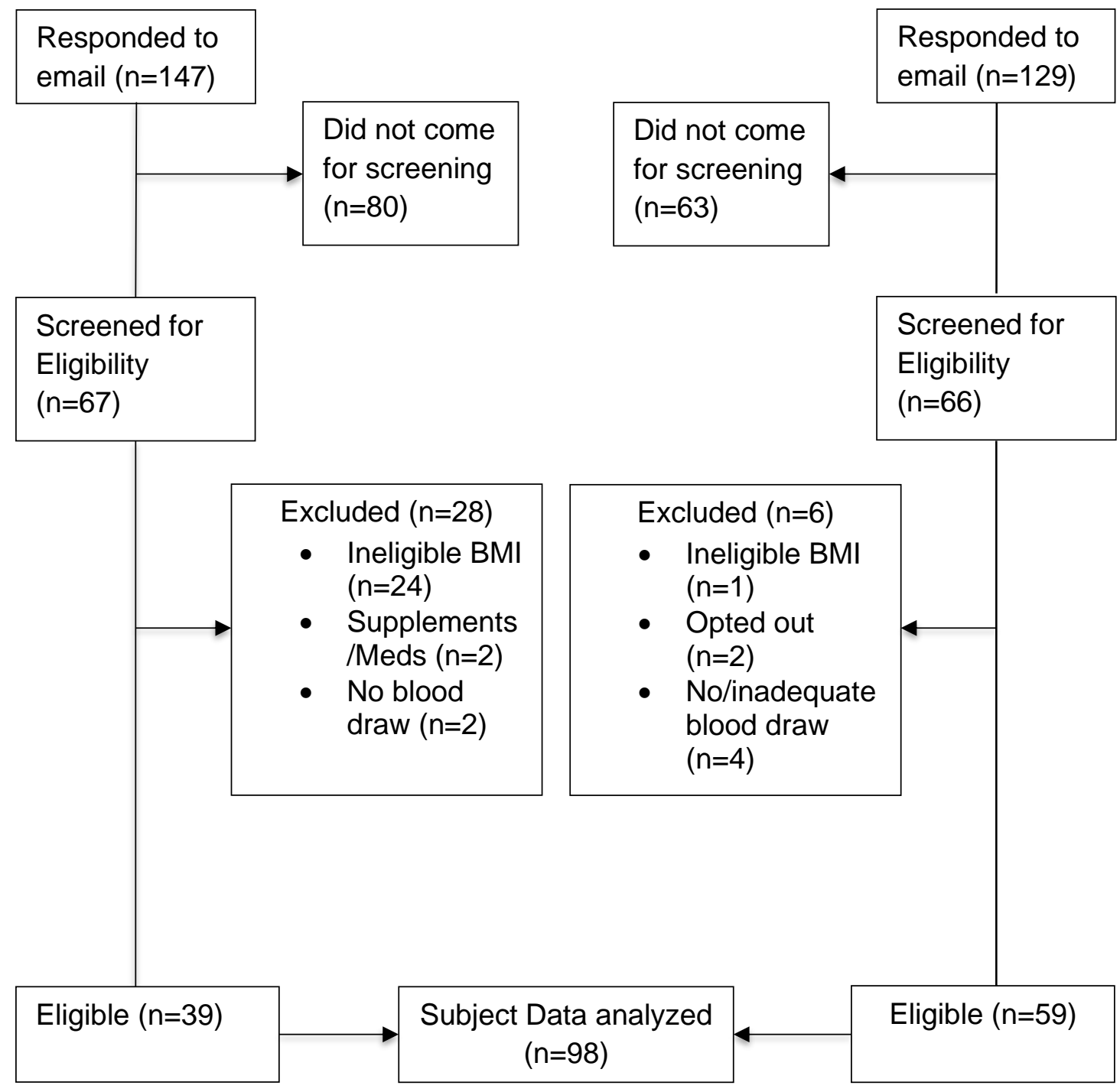




\section{Data Collection}

For each of the two studies, qualified participants were provided with a dietary record form, food frequency questionnaire, and a weighing scale and were required to record all foods consumed on three non-consecutive days of which two were weekdays and one was a weekend day. At the follow-up study visit, anthropometric measurements were repeated, a 10h fasted venous blood (approximately $30 \mathrm{ml}$ ) was collected and participants submitted their completed three-day dietary records. The dietary records and food frequency questionnaires were reviewed with each participant by trained research assistants.

Dietary data from the three-day dietary records were analyzed into nutrients using the Nutrition Data System for Research (University of Minnesota, MN, USA) and used in calculating the DII scores. Up to 45 food components can be used for calculating DII scores. Thirty of these were available from the NDSR data and were used in the analyses of this study (Table 1). These included: fiber, vitamin B6, folic Acid, niacin, riboflavin, thiamin, beta carotene, vitamin A, vitamin D, vitamin E, vitamin C, caffeine, alcohol, selenium, magnesium, zinc, isoflavones, MUFA, Omega 3, Omega 6, PUFA, total fat, trans fat, saturated fat, iron, carbohydrate, protein, cholesterol, Energy, vitamin B12. The first twenty-one components were considered anti-inflammatory and the remaining considered inflammatory. The DII calculations were done at the Cancer Prevention and Control Program Center at the University of South Carolina as previously described (45). 
For each participant, some of the fasted blood samples were sent to LabCorp (Burlington, NC) after processing for the measurement of hemoglobin, iron saturation, serum iron, total iron binding capacity (TIBC), serum ferritin and C-reactive protein concentration (CRP). The remaining were stored at $-80{ }^{\circ} \mathrm{C}$ at $\mathrm{UNCG}$ for the measurement of hepcidin concentration at the end of each study. Hepcidin was analyzed using ELISA assay kit from Peninsula Laboratories International (San Carlos, CA, USA).

Table 1. Food Components of DII Scoring Algorithm

\begin{tabular}{|ll|l|}
\hline Anti-inflammatory & & Pro inflammatory \\
\hline Alcohol & Folic acid & Total fat \\
n-3-fatty acids & Selenium & Vitamin B $_{12}$ \\
Vitamin E & Flavonones & Carbohydrate \\
Vitamin B 6 & Garlic & Cholesterol \\
n-6 fatty acids & Thiamin & Energy \\
Zinc & Anthocyanidins & Iron \\
B-Carotene & Ginger & Protein \\
Onion & Turmeric & Saturated fat \\
Green/black tea & Isoflavones & Trans Fat \\
Caffeine & Magnesium & \\
PUFA & Vitamin A & \\
Flavan-3-ol & Pepper & \\
Eugenol & MUFA & \\
Riboflavin & Vitamin C & \\
Flavones & Thyme/oregano & \\
Fiber & Niacin & \\
Saffron & Vitamin D & \\
Flavonols & Rosemary & \\
& & \\
& & \\
\end{tabular}

Subjects were categorized has having normal weight $\left(18.5-24.9 \mathrm{~kg} / \mathrm{m}^{2}\right)$, overweight $(25-$ $29.9 \mathrm{~kg} / \mathrm{m}^{2}$ ) or obesity ( above $30 \mathrm{~kg} / \mathrm{m}^{2}$ ) according to established BMI criteria. To 
categorize the DII scores into either pro inflammatory or anti-inflammatory diet group, we used cluster analysis.

\section{Statistical Methods}

Statistical analyses were done using the R statistical software (183).. DII scores were treated both as a continuous variable and as a categorical variable for the purpose of investigating all possible relationships between the DII and the primary outcome variables which were serum iron, TIBC, hepcidin concentration and CRP concentration. To categorize the DII score into either a pro inflammatory or anti-inflammatory diet group, we chose cluster analysis with only two groups to ensure adequate sample size for each group. Percentages were reported for categorical variables such as sex, ethnicity and BMI categories. Hepcidin, ferritin, and transferrin saturation values were used for post hoc analyses. The means and standard error of mean (SEM) were reported for the continuous variables such as age, BMI, serum iron, hemoglobin, TIBC, transferrin saturation and for the concentrations of ferritin, hepcidin, and CRP. Skewed variables were log transformed and the geometric means were reported. Fisher's exact test and ANOVA were used to compare background characteristics. Where ANOVS showed statistical significance, Tukey's HSD was used for multiple comparison. Linear regression analysis was used to determine the association among the DII as an independent variable with CRP, hepcidin concentration, serum iron and TIBC. All regression models were adjusted for age, gender, and ethnicity. We also adjusted for 
meat, fish and poultry intake where necessary since iron intake was considered proinflammatory in the DII calculations. Statistical significance was set at $\mathrm{P} \leq 0.05$.

\section{Results}

\section{Background Characteristics of Subjects}

Participant background characteristics grouped by BMI category are displayed in (Table 2). The overall mean age was $21.0 \pm 0.4 \mathrm{y}$ and the majority of the subjects (72 of the 98) were female. Despite higher female representation, the distribution of both sexes among BMI categories was not significantly different. $(\mathrm{p}=0.6)$. Similarly, there was no significant association between BMI category and ethnicity $(\mathrm{p}=0.7)$. BMI categories were also well represented with $29 \%$ of subjects having normal weight, $40 \%$ having overweight and $32 \%$ having obesity status (total percentage not equal to 100 due to rounding).

Table 2. Background Characteristics According to BMI

\begin{tabular}{|l|c|c|c|c|c|}
\hline \multirow{2}{*}{} & \multicolumn{4}{|c|}{ BMI $\left(\mathrm{kg} / \mathrm{m}^{2}\right)$ category } & \multirow{2}{*}{ P-Value } \\
\cline { 2 - 5 } & $\begin{array}{c}\text { Normal } \\
18.5-24.9 \\
\mathrm{~N}=28\end{array}$ & $\begin{array}{c}\text { Overweight } \\
25-29.9 \\
\mathrm{~N}=39\end{array}$ & $\begin{array}{c}\text { Obese } \\
\geq 30 \\
\mathrm{~N}=31\end{array}$ & $\begin{array}{c}\text { Total } \\
\mathrm{N}=98\end{array}$ & \\
\cline { 1 - 5 } & $21.2 \pm 0.4$ & $21.4 \pm 0.7$ & $21.8 \pm 0.6$ & $21 \pm 0.4$ & \multirow{2}{*}{0.8} \\
\hline Age (y) & $8(8.16 \%)$ & $9(9.18 \%)$ & $10(10.20 \%)$ & $27(27.55 \%)$ & \multirow{2}{*}{0.6} \\
\hline Mex ${ }^{1}$ & $20(20.41 \%)$ & $30(30.61 \%)$ & $21(21.43 \%)$ & $71(72.44 \%)$ & \\
\hline Female & & & & & \\
\hline
\end{tabular}




\begin{tabular}{|c|c|c|c|c|c|}
\hline Ethnicity ${ }^{1}$ & & & & & 0.7 \\
\hline Hispanic & $3(3.06 \%)$ & $4(4.08 \%)$ & $4(4.08 \%)$ & $11(11.22 \%)$ & \\
\hline NH White & $14(14.29 \%)$ & $11(11.22 \%)$ & $13(13.27 \%)$ & $38(38.78 \%)$ & \\
\hline NH Black & $6(6.12 \%)$ & $13(12.27 \%)$ & $16(16.33 \%)$ & $35(35.71 \%)$ & \\
\hline Other & $5(5.10 \%)$ & $3(3.06 \%)$ & $6(6.12 \%)$ & $14(14.29 \%)$ & \\
\hline $\begin{array}{l}\mathrm{BMI}^{1}, \\
\mathrm{~kg} / \mathrm{m}^{2}\end{array}$ & $22.5 \pm 0.3 \mathrm{a}$ & $27.0 \pm 0.24 \mathrm{~b}$ & $34.9 \pm 0.50 \mathrm{c}$ & $28 . \pm 0.5$ & $<0.0001$ \\
\hline
\end{tabular}
geometric mean + SEM)

\section{Nutrient Intakes and DII Scores among Subjects}

DII scores and the median intakes of selected nutrients including iron, MFP (meat, fish, poultry), protein, fiber and fat by BMI category are reported in (Table 3). There were no significant differences among BMI categories for the nutrients reported. Among all participants, the DII scores ranged from a maximally antiinflammatory score of -4.2 to a maximally proinflammatory score of 3.7 . Cluster analysis of the scores grouped them into distinctly anti (-4.2 to 0.7$)$ or pro inflammatory (0.8 to 3.7) groups for bivariate comparisons. 
Table 3. Selected Nutrient Intakes and DII Scores According to BMI

\begin{tabular}{|c|c|c|c|c|}
\hline Factor/Nutrient & Normal Weight & Overweight & Obese & P-value \\
& & & & \\
\hline Iron, mg & $16.87(9.37$, & $12.25(9.72$, & $15.68(9.70$, & 0.166 \\
& $19.43)$ & $14.79)$ & $20.20)$ & \\
\hline MFP (ounces) & $3.56(2.20$, & $5.92(3.57$, & $4.59(3.02$, & 0.06 \\
& $6.25)$ & $7.99)$ & $7.05)$ & \\
\hline Calories, kcals & $1779(1426$, & $1875(1433$, & $2229(1591$, & 0.43 \\
& $2527)$ & $2209)$ & $2628)$ & \\
\hline Protein, g & $74.45(50.26$, & $74.09(51.91$, & $74.87(71.30$, & 0.48 \\
& $96.49)$ & $98.30)$ & $97.42)$ & \\
\hline Fiber, g & $17.28(11.70$, & $14.41(11.76$, & $16.68(12.20$, & 0.24 \\
& $21.73)$ & $17.18)$ & $22.16)$ & \\
\hline Fat, g & $67.89(56.50$, & $74.75(52.97$, & $95.05(63.93$, & 0.31 \\
& $106.32)$ & $97.27)$ & $113.71)$ & \\
\hline DII Score & $1.02(1.19$, & $0.97(0.18$, & $1.01(0.47$, & 0.8 \\
& $1.97)$ & $2.04)$ & $1.96)$ & \\
\hline
\end{tabular}

\section{Inflammatory and Iron Status Biomarkers}

CRP concentration was highest among the subjects with obesity $[3.63(2.98,4.43)$

$\mathrm{mg} / \mathrm{L}]$, and lowest among subjects with normal weight $[0.40(0.32,0.48) \mathrm{mg} / \mathrm{L}](\mathrm{P}<0.05$

for all comparisons) (Table 4). A trend toward poor iron status as BMI category increased was reflected in most iron status biomarkers (serum iron, Tsat and TIBC), however, only serum iron was significantly higher in normal weight $(103 \pm 10 \mu \mathrm{g} / \mathrm{d})$ compared to obesity $(72.6 \pm 6 \mu \mathrm{g} / \mathrm{d})$ category $(\mathrm{p}=0.01)$. Hepcidin concentrations were nearly twice as high in subjects with obesity compared to those with normal weight but this was not significant $(\mathrm{p}=0.06)$. 
Table 4. Inflammatory and Iron Status Biomarkers According to BMI

\begin{tabular}{|c|c|c|c|c|c|}
\hline \multirow{2}{*}{} & \multicolumn{4}{|c|}{ BMI $\left(\mathrm{kg} / \mathrm{m}^{2}\right)$ category } & \multirow{2}{*}{ P-value } \\
\cline { 2 - 5 } & $\begin{array}{c}18.5-24.9 \\
\mathrm{~N}=29\end{array}$ & $\begin{array}{c}25-29.9 \\
\mathrm{~N}=39\end{array}$ & $\begin{array}{c}\geq 30 \\
\mathrm{~N}=31\end{array}$ & $\begin{array}{c}\text { Total } \\
\mathrm{N}=98\end{array}$ & \\
\hline $\mathrm{CRP}^{1}(\mathrm{mg} / \mathrm{L})$ & $\begin{array}{c}0.4(0.3, \\
0.5)^{\mathrm{a}}\end{array}$ & $\begin{array}{c}0.8(0.7, \\
1.0)^{\mathrm{b}}\end{array}$ & $\begin{array}{c}3.6(3.0, \\
4.4)^{\mathrm{c}}\end{array}$ & $\begin{array}{c}1.1(0.9, \\
1.2)\end{array}$ & $<0.0001$ \\
\hline Ferritin ${ }^{1}(\mathrm{ng} / \mathrm{ml})$ & $37(31,45)$ & $33(28,39)$ & $51(43,61)$ & $39(35,49)$ & 0.2 \\
\hline $\begin{array}{c}\text { Serum iron } \\
(\mu \mathrm{g} / \mathrm{dL})\end{array}$ & $103 \pm 10^{\mathrm{a}}$ & $83 \pm 6^{\mathrm{a}, \mathrm{b}}$ & $72 \pm 6^{\mathrm{b}}$ & $85 \pm 4$ & 0.014 \\
\hline $\begin{array}{c}\text { Transferrin } \\
\text { saturation }(\%)\end{array}$ & $31.3 \pm 3.4$ & $26.1 \pm 1.9$ & $23.0 \pm 2.0$ & $26.6 \pm 1.4$ & 0.07 \\
\hline $\begin{array}{c}\text { Hemoglobin } \\
(\mathrm{g} / \mathrm{dL})\end{array}$ & $13.6 \pm 0.3$ & $13.1 \pm 0.4$ & $13.5 \pm 0.3$ & $13.4 \pm 0.2$ & 0.6 \\
\hline \begin{tabular}{c} 
TIBC ( $\mu \mathrm{gg} / \mathrm{dL})$ \\
\hline $\begin{array}{c}\text { Hepcidin } \\
(\mathrm{ng} / \mathrm{ml})\end{array}$
\end{tabular} & $355 \pm 15$ & $346 \pm 8$ & $344 \pm 12$ & $348 \pm 6$ & 0.8 \\
\hline
\end{tabular}

${ }^{1}$ Data were log transformed. Values are geometric means (geometric mean -1SE, geometric mean $+1 \mathrm{SE}$ )

Associations of DII with CRP and Hepcidin Concentrations

Using linear regression, we investigated the association between the DII scoring as a continuous variable and inflammation as assessed using CRP concentration (Table 5). We found that $\mathrm{CRP}$ concentration increased with increasing DII score $(\beta \pm \mathrm{SE}=$ $0.23 \pm 0.07, \mathrm{p}=0.002)$ and that caloric intake also predicted $\mathrm{CRP}$ concentration $(\beta \pm \mathrm{SE}=$ 
$0.54 \pm 0.17, \mathrm{p}=0.002)$. In this model, having overweight $(\beta \pm \mathrm{SE}=0.63 \pm 0.26, \mathrm{p}=0.020)$ or obesity $((\beta \pm \mathrm{SE}=2.17 \pm 0.28, \mathrm{p}<0.001)$ was associated with higher CRP compared to subjects having normal weight.

We also determined the association between DII as a categorical variable and CRP concentration (Table 6). In this model, the relationship between DII category and $\mathrm{CRP}$ was not statistically significant $(\beta \pm \mathrm{SE}=-0.45 \pm 0.25, \mathrm{p}=0.076)$. Also, although the anti-inflammatory diet category was associated with lower hepcidin concentration, this was not statistically significant $(\beta \pm \mathrm{SE}=-0.29 \pm 0.17 ; \mathrm{p}=0.095)$.

Table 5. Associations of DII Scores with CRP and Hepcidin

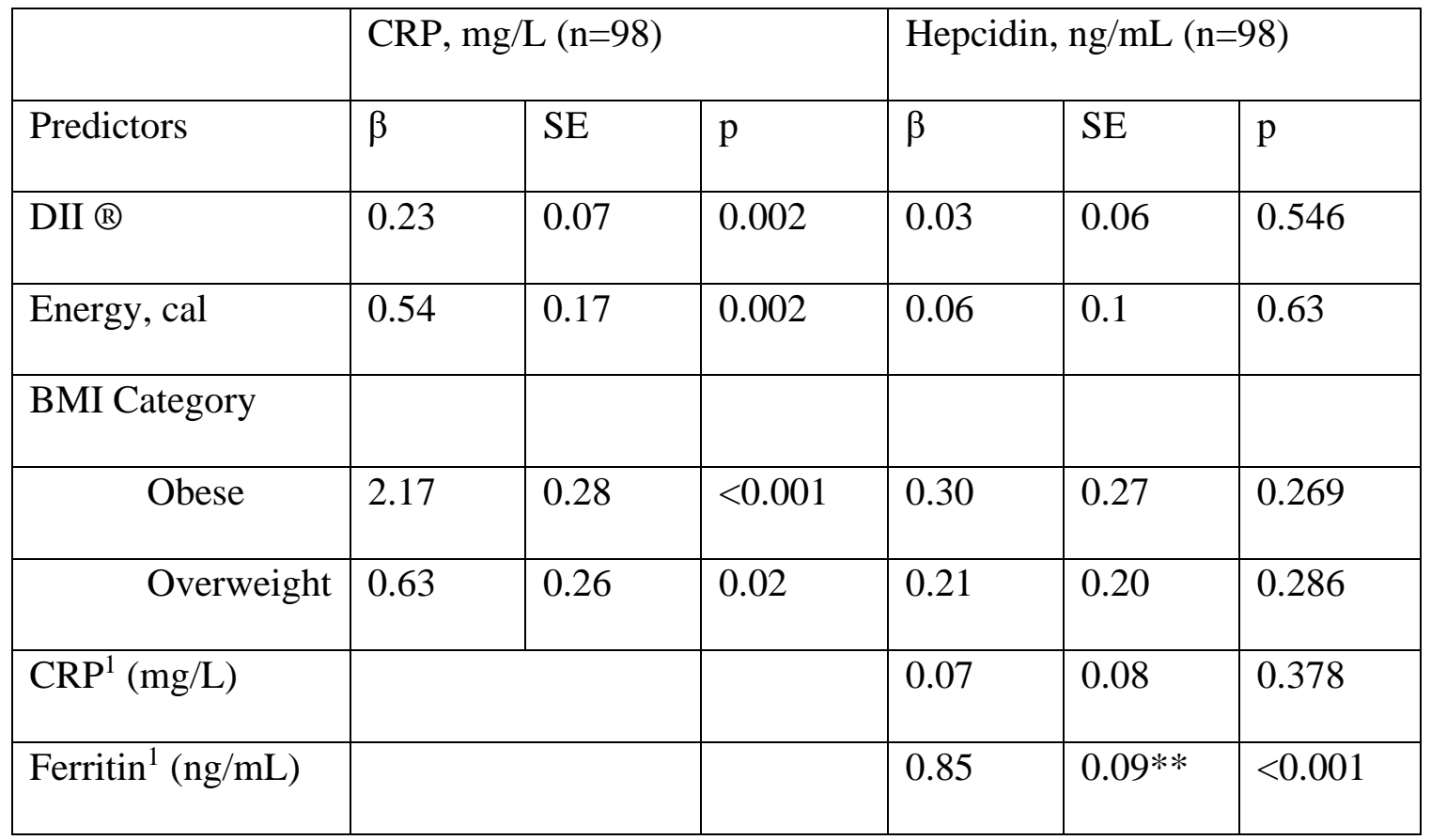

Regression models were adjusted for age, sex and ethnicity. DII $=$ Dietary Inflammatory Index

${ }^{1}$ Data were $\log$ transformed. 
Table 6. Associations of DII Category with CRP and Hepcidin

\begin{tabular}{|l|l|l|l|l|l|l|}
\hline & \multicolumn{3}{|c|}{ CRP (mg/L) } & \multicolumn{3}{c|}{ Hepcidin (ng/mL) } \\
\hline Predictors & $\beta$ & SE & $p$ & $\beta$ & SE & $p$ \\
\hline DII category & -0.45 & 0.25 & 0.076 & -0.29 & 0.17 & 0.095 \\
\hline $\begin{array}{l}\text { Anti- } \\
\text { inflammatory }\end{array}$ & 0.4 & 0.1 & 0.018 & 0.1 & 0.1 & 0.383 \\
\hline Energy, cals & 0.4 & & & & & \\
\hline $\begin{array}{l}\text { BMI } \\
\text { category }\end{array}$ & 2.25 & 0.29 & $<0.001$ & 0.33 & 0.26 & 0.214 \\
\hline Obese & 0.72 & 0.27 & 0.010 & 0.24 & 0.19 & 0.225 \\
\hline Overweight & & & & 0.06 & 0.07 & 0.411 \\
\hline CRP ${ }^{1}(\mathrm{mg} / \mathrm{L})$ & & & & 0.85 & 0.09 & $<0.001$ \\
\hline $\begin{array}{l}\text { Ferritin } \\
\text { (ng/dL) }\end{array}$ & & & & & & \\
\hline
\end{tabular}

Regression models were adjusted for age, sex and ethnicity DII = Dietary Inflammatory Index

${ }^{1}$ Data were log transformed. Values are geometric means (geometric mean -1SE, geometric mean + 1SE)

Associations of Inflammatory Diets with Iron Status Biomarkers

DII score was an independent predictor of TIBC when analyzed as a continuous variable $((\beta \pm \mathrm{SE}=-8.46 \pm 3.44, \mathrm{p}=0.016)$ (Table 7). DII scores were not however related to serum iron. Only the obese category was predictive of lower serum iron while ferritin concentration predicted higher serum iron and lower TIBC. Anti-inflammatory diets 
were associated with high TIBC $(\beta \pm \mathrm{SE}=29.87 \pm 10.75, \mathrm{p}=0.007)($ Table 8$)$. This relationship was independent of other iron status biomarkers.

Table 7. Associations of DII Scores with Iron Status Biomarkers

\begin{tabular}{|l|l|l|l|l|l|l|}
\hline & \multicolumn{5}{|l|}{ Serum iron, $\mu \mathrm{g} / \mathrm{dL}(\mathrm{n}=97)$} & \multicolumn{2}{l}{ TIBC, $\mu \mathrm{g} / \mathrm{dL}(\mathrm{n}=98)$} \\
\hline Predictors & $\beta$ & $\mathrm{SE}$ & $\mathrm{p}$ & $\beta$ & $\mathrm{SE}$ & $\mathrm{p}$ \\
\hline DII $®$ & 1.98 & 2.63 & 0.454 & -8.46 & 3.44 & 0.016 \\
\hline Energy, Cal & 0.00 & 0.01 & 0.720 & 0.00 & 0.01 & 0.809 \\
\hline BMI Category & & & & & & \\
\hline \multicolumn{1}{|c|}{ Obese } & -27.11 & 12.31 & 0.030 & -4.16 & 16.36 & 0.80 \\
\hline \multicolumn{1}{|c|}{ Overweight } & -14.24 & 9.18 & 0.125 & -12.43 & 12.05 & 0.305 \\
\hline CRP ${ }^{1}$ mg/L & -4.99 & 3.61 & 0.171 & 5.14 & 4.79 & 0.287 \\
\hline Ferritin ${ }^{1}$ ng/mL & 14.55 & 4.30 & 0.001 & -43.33 & 5.71 & $<0.001$ \\
\hline
\end{tabular}

Regression models were adjusted for age, sex, ethnicity and MFP.

${ }^{1} \mathrm{CRP}=\mathrm{C}$-Reactive Protein

$\mathrm{DII}=$ Dietary Inflammatory index 
Table 8. Associations of DII Category with Iron Status Biomarkers

\begin{tabular}{|c|c|c|c|c|c|c|}
\hline & \multicolumn{3}{|c|}{ Serum iron, $\mu \mathrm{g} / \mathrm{dL}(\mathrm{n}=97)$} & \multicolumn{3}{|c|}{ TIBC, $\mu \mathrm{g} / \mathrm{dL}(\mathrm{n}=98)$} \\
\hline & $\beta$ & SE & $\mathrm{p}$ & $\beta$ & SE & $\mathrm{p}$ \\
\hline \multicolumn{7}{|l|}{ DII Category } \\
\hline Anti-inflammatory & 2.03 & 8.20 & 0.805 & 29.87 & 10.75 & 0.007 \\
\hline Energy, Cal & -0.00 & 0.01 & 0.867 & 0.00 & 0.01 & 0.552 \\
\hline \multicolumn{7}{|l|}{ BMI Category } \\
\hline Obese & -29.03 & 12.28 & 0.020 & -3.03 & 16.10 & 0.851 \\
\hline Overweight & -14.15 & 9.23 & 0.129 & -15.23 & 11.98 & 0.207 \\
\hline $\mathrm{CRP}^{1} \mathrm{mg} / \mathrm{L}$ & -3.93 & 3.48 & 0.262 & 3.57 & 4.55 & 0.435 \\
\hline Ferritin $^{1} \mathrm{ng} / \mathrm{mL}$ & 15.33 & 4.24 & $<0.001$ & -44.58 & 5.57 & $<0.001$ \\
\hline
\end{tabular}

Regression models were adjusted for age, sex, ethnicity, and MFP intake.

${ }^{1} \mathrm{CRP}=\mathrm{C}$-Reactive Protein

DII= Dietary Inflammatory index

Data were log transformed.

\section{Discussion}

Systemic inflammation can be triggered by several factors including diet and obesity $(44,177,184,185)$ and can lead to adverse health outcomes such as type 2 diabetes and cardiovascular diseases. Recent studies have shown that inflammation may also play a role in iron status regulation through the protein hepcidin. For example, low grade inflammation in obesity has been implicated in the poor iron status observed among individuals with obesity $(23,169,179,186,187)$. While diets may play a role in iron status 
through their heme and nonheme iron contents, it is not clear if their inflammatory and anti-inflammatory properties also influence iron status. In this study, we investigated the relationship between the inflammatory score of diets assessed using the DII and circulating iron biomarkers, namely serum iron and TIBC, adjusting for obesity status and other potential confounders. We chose the circulating iron biomarkers because elevated hepcidin concentration directly reduces circulating iron through poor iron absorption or iron sequestration $(91,176,188)$.

Median nutrient intakes in our studies were not significantly different among the three BMI categories (normal weight, overweight and obese). Compared to other studies (189), we found a much higher median MFP intake in our study population (5.08 ounces or $142 \mathrm{~g}$ vs $91 \mathrm{~g}$ ) despite similarities in age group. This is due to the fact that the dietary intakes of subjects in their study were modified in some cases. On the other hand, fiber intake data by BMI in our study is similar to those among US college students reported by Garcia-Meseguer (190) in a study of fiber patterns among college students in three different countries (Spain, USA and Tunisia). They observed median fiber intakes among USA students of $18.1 \mathrm{~g}, 15.3 \mathrm{~g}$ and $18.3 \mathrm{~g}$ in normal weight, overweight, and obese participants respectively compared to $17.28,14.41$ and 16.68 among our study participants.

DII scores in our study ranged from -4.44 to 3.49 with median of 0.99 . The lowest DII score in this study compares favorably to the -4.93 minimum DII score reported in another study among young adults (21-35y) living in southeastern US (South Carolina) 
(191), although they reported DII scores much higher than our maximum value of 3.49. Median DII scores in our study did not differ significantly among the different BMI categories $(\mathrm{p}=0.8)$. In a study of associations between body weight and dietary inflammation, Muhammad et al. (192) also found no associations between BMI and DII as a continuous variable or with DII tertile. While these support our findings, the contrary was reported by Ruiz-Canela et al. (193) who found a positive association between the two variables in a population with high risk for CVD. In this study, the correlation was found only among women and all the study participants were at least $55 \mathrm{y}$. In a college setting similar to our study, Kim et al.(194) compared DII scoring with HEI and glycemic index scores. In their study, DII was positively correlated with glycemic index (GI) and inversely correlated with HEI. Wirth et al., also reported negative correlations between the DII scores of young adults and the HEI-2010 $(r=-0.65, \mathrm{P}<.01)$, AHEI $(\mathrm{r}=-0.55$,P $<.01)$, as well as the DASH diet $(\mathrm{r}=-0.52, \mathrm{P}<.01)$. Even though DII scores were also not associated with BMI, lower DII values were found in individuals with the lowest waist-to-hip ratios (WHR), a reliable indicator of central adiposity (195-198). However we did not have WHR measures for our analyses.

In our study, geometric mean of CRP was $1.1 \mathrm{mg} / \mathrm{L}(0.9,1.2)$. In two recent studies of young adults, mean CRP was found to be $1.72 \mathrm{mg} / \mathrm{L}$ and $1.5 \mathrm{mg} / \mathrm{L}$ $(199,200)$. Our lower value may be due to the fact that we reported the geometric mean, while these studies reported the arithmetic mean. Our findings showed that CRP concentration increased with BMI category, being highest in the obese category and 
lowest in the normal weight category. This affirms what has been reported in several earlier studies $(201,202)$.

We also found in a positive association between DII score and CRP concentration, which attests to the ability of the DII score to predict inflammation. Our results also corroborate the findings from several other studies $(164,167,200,201)$. For example, Boden et al. (203) observed that DII predicted $1.7 \%$ of elevated CRP in a prospective case control study of 1,389 verified cases of first myocardial infarction (MI). Wirth et al. (167) reported positive associations between DII scores and CRP levels among African Americans in the fourth quartile of DII category in baseline data of the Healthy Eating and Active Living in the Spirit (HEALS) intervention study. In our regression analyses that included DII scores, both DII scores and overweight and obesity status categories were predictors of CRP suggesting that diet in addition to increased adiposity may contribute to the higher CRP among young adults. Dietary factors are shown to trigger inflammation via NFk- $\beta$ activation and subsequent induction of inflammatory cytokines through upregulated innate immune signaling of toll like receptors-4 (TLR-4) and via the NRLP3 complex $(124,154,204)$. High fat diets, particularly those high in saturated and trans fatty acids are shown to increase inflammation in mouse models and human studies while diets low in animal products are known to be anti-inflammatory. In an early mouse model, Lumeng et al. (205) found that a high-fat diet increases the inflammatory properties of macrophages recruited by adipose tissue in obese compared to lean mice. In a later study, Kim et al. (206) reported 
increased systemic inflammation and acceleration of adiposity via increased TLR4 signaling by high fat diet induced endotoxemia in the intestinal lumen of mice. In humans, a recent meta-analysis that controlled for weight loss reported that plant-based diets were independently associated with reductions in CRP in subjects with obesity (207).

We also compared iron status and inflammatory markers among the different BMI categories. While other iron status biomarkers did not differ significantly, serum iron was significantly lower among subjects with obesity compared to those with normal weight $(\mathrm{p}=0.014)$. It is well documented that obesity is a risk factor for poor iron status $(19,170,172,208)$ and the impaired iron status in obesity has been attributed to factors such as inflammation and concomitant elevated hepcidin concentration. Citelli et al. (179) reported increased hepcidin gene expression and iron accumulation in spleen and liver tissues as well as reductions in ferroportin (FPN) gene expression in obese mice fed a high fat diet. In humans, a combined cross-sectional and longitudinal case control study by Moreno-Navarette et al.,(188) reported increased serum hepcidin, ferritin and hepatic iron content (HIC) among patients with obesity along with subsequent improvement in these values after dietary weight loss interventions. Chang et al. (2014 REF) observed associations of fat to carbohydrate ratios with BMI among women with iron deficiency anemia (IDA) but not among healthy women. Their findings showed a positive relationship between BMI and fat consumption $(\mathrm{p}=0.035)$ and an inverse relationship between BMI and CHO intake $(p=0.045)$ only in women with IDA. These 
studies suggest that obesity alone is not responsible for the alterations of iron metabolism in obesity $(15,209,210)$. Therefore, in the present study we investigated how dietary inflammation, assessed through the DII scoring methodology, influences iron status independent of obesity related inflammation.

During inflammation, the iron transport protein transferrin is a negative acute phase protein, and its production, therefore is downregulated, reducing its concentration (211-214). In a female rat model, Zeid et al. (215) observed reduced TIBC in obese Wistar rats fed a high fat diet compared to control non obese mice fed standard chow. The researches also reported lower serum iron and transferrin saturation in high fat diet. This same study reported increased hepcidin, IL-6, ferritin and plasma leptin in the obese rats compared to control. In the regression analyses of our study, higher DII scores predicted lower TIBC levels which suggests lower transferrin levels among subjects whose diets were estimated to have had higher inflammatory effects. TIBC is reduced in both iron replete and inflammatory states. Since our analyses controlled for meat, poultry, fish intake and as well as for other iron status biomarkers, it is more likely that the inflammatory effects of the diet predicted reduced TIBC rather than increased iron intake.

\section{Limitations}

While data from the present study were from mostly female subjects (72\%) which could affect the value of the iron status biomarkers, we did not find a significant difference in sex distribution among the different BMI categories. Another consideration 
of this study's results is that the current version of the DII which is weighted toward antiinflammatory components does not score more recently studied food components such as added sugars, non-nutritive sweeteners and advanced glycation end products which were common among the dietary records of the study's sample. Future studies are needed to determine the effects of dietary inflammation on transferrin production by the liver, as well as longitudinal investigations into how added sugars, non-nutritive sweeteners and the cooking effects of manufactured edible oils may influence inflammatory and micronutrient status.

\section{Conclusion}

In conclusion, we are the first to use the DII to examine the inflammatory effects of diet on circulating iron biomarkers and to demonstrate a relationship between inflammatory diets and decreased TIBC. While it may be easy to presume that the effects of weight gain, including increased adiposity, alone account for poor health outcomes, lifestyle factors such as diet and activity patterns may play a key differentiating role. In this study we have demonstrated that diet, independent of body weight status, predicts inflammation among young adults. This implies that less inflammatory diets can be prescribed for reducing inflammation in all patients independent of weight status and for improving outcomes in chronic diseases. 


\section{REFERENCES}

1. Moghe A, Ghare S, Lamoreau B, Mohammad M, Barve S, McClain C, Joshi-Barve S. Molecular Mechanisms of Acrolein Toxicity: Relevance to Human Disease. Toxicol Sci. 2015;143:242-55.

2. Choi S-W, Tammen SA, Liu Z, Friso S. A lifelong exposure to a Western-style diet, but not aging, alters global DNA methylation in mouse colon. Nutr Res Pract. 2015;9:358-63.

3. Naruszewicz M, Zapolska-Downar D, Kośmider A, Nowicka G, KozłowskaWojciechowska M, Vikström AS, Törnqvist M. Chronic intake of potato chips in humans increases the production of reactive oxygen radicals by leukocytes and increases plasma C-reactive protein: a pilot study. Am J Clin Nutr. 2009;89:773-7.

4. Huang EY, Devkota S, Moscoso D, Chang EB, Leone VA. The role of diet in triggering human inflammatory disorders in the modern age. Microbes Infect. 2013;15:765-74.

5. Kolberg M, Pedersen S, Mitake M, Holm KL, Bøhn SK, Blomhoff HK, Carlsen H, Blomhoff R, Paur I. Coffee inhibits nuclear factor-kappa B in prostate cancer cells and xenografts. J Nutr Biochem. 2016;27:153-63.

6. Zheng M, Zou C, Li M, Huang G, Gao Y, Liu H. Folic Acid Reduces Tau Phosphorylation by Regulating PP2A Methylation in Streptozotocin-Induced Diabetic Mice. Int J Mol Sci Basel. 2017;18:861.

7. Yoon CS, Kim MK, Kim YS, Lee SK. In vitro protein expression changes in RAW 264.7 cells and HUVECs treated with dialyzed coffee extract by immunoprecipitation high performance liquid chromatography. Sci Rep. 2018;8:13841.

8. Wagner AE, Terschluesen AM, Rimbach G. Health Promoting Effects of BrassicaDerived Phytochemicals: From Chemopreventive and Anti-Inflammatory Activities to Epigenetic Regulation. Oxid Med Cell Longev [Internet]. 2013 [cited 2018 Oct 25];2013. Available from: https://www.ncbi.nlm.nih.gov/pmc/articles/PMC3885109/

9. Kim JK, Park JH, Ku HJ, Kim SH, Lim YJ, Park JW, Lee JH. Naringin protects acroleininduced pulmonary injuries through modulating apoptotic signaling and inflammation signaling pathways in mice. J Nutr Biochem. 2018;59:10-6.

10. Berry intake changes hepatic gene expression and DNA methylation patterns associated with high-fat diet. J Nutr Biochem. 2016;27:79-95. 
11. Mauer J, Denson JL, Brüning JC. Versatile functions for IL-6 in metabolism and cancer. Trends Immunol. 2015;36:92-101.

12. Hunter CA, Jones SA. IL-6 as a keystone cytokine in health and disease. Nat Immunol N Y. 2015;16:448-57.

13. Li J, Xiao C, Yang H, Zhou Y, Wang R, Cao Y. Anemia and Iron Status Among Different Body Size Phenotypes in Chinese Adult Population: a Nation-Wide, Health and Nutrition Survey. Biol Trace Elem Res. 2018;185.

14. Cepeda-Lopez AC, Melse-Boonstra A, Zimmermann MB, Herter-Aeberli I. In overweight and obese women, dietary iron absorption is reduced and the enhancement of iron absorption by ascorbic acid is one-half that in normal-weight women. Am J Clin Nutr. 2015;102:1389-97.

15. Arshad M, Jaberian S, Pazouki A, Riazi S, Rangraz MA, Mokhber S. Iron deficiency anemia and megaloblastic anemia in obese patients. Romanian J Intern Med Rev Roum Med Interne. 2017;55:3-7.

16. Khan A, Khan WM, Ayub M, Humayun M, Haroon M. Ferritin Is a Marker of Inflammation rather than Iron Deficiency in Overweight and Obese People. J Obes N Y [Internet]. 2016 [cited 2018 Jun 26]; Available from:

http://search.proquest.com/docview/1862241992/abstract/5050786C01444490PQ/1

17. Yanoff LB, Menzie CM, Denkinger B, Sebring NG, McHugh T, Remaley AT, Yanovski JA. Inflammation and iron deficiency in the hypoferremia of obesity. Int J Obes. 2007;31:1412-9.

18. Ferrari M, Cuenca-Garcia M, Valtuena J, Moreno LA, Censi L, Gonzalez-Gross M, Androutsos O, Gilbert CC, Huybrechts I, Dallongeville J, et al. Inflammation profile in overweight/obese adolescents in Europe: an analysis in relation to iron status [Internet]. European Journal of Clinical Nutrition. 2015 [cited 2018 Sep 6]. Available from: http://link.galegroup.com/apps/doc/A400415459/AONE?sid=googlescholar

19. Cheng HL, Bryant C, Cook R, O’Connor H, Rooney K, Steinbeck K. 21) The relationship between obesity and hypoferraemia in adults: a systematic review. Obes Rev. 2012;13:150-61.

20. McNelis JC, Olefsky JM. Macrophages, Immunity, and Metabolic Disease. Immunity. 2014;41:36-48.

21. Shimobayashi M, Albert V, Woelnerhanssen B, Frei IC, Weissenberger D, MeyerGerspach AC, Clement N, Moes S, Colombi M, Meier JA, et al. Insulin resistance causes inflammation in adipose tissue. J Clin Investig Ann Arbor. 2018;128:1538-50. 
22. Zhao L, Zhang X, Shen Y, Fang X, Wang Y, Wang F. Obesity and iron deficiency: a quantitative meta-analysis. Obes Rev. 16:1081-93.

23. Kaner G, Pekcan G, Pamuk G, Pamuk BÖ, Amoutzopoulos B. Is iron deficiency related with increased body weight? A cross-sectional study. Prog Nutr. 2016;18:102-10.

24. Sido A, Radhakrishnan S, Kim SW, Eriksson E, Shen F, Li Q, Bhat V, Reddivari L, Vanamala JKP. A food-based approach that targets interleukin-6, a key regulator of chronic intestinal inflammation and colon carcinogenesis. J Nutr Biochem. 2017;43:11-7.

25. Meli R, Mattace Raso G, Irace C, Simeoli R, Di Pascale A, Paciello O, Pagano TB, Calignano A, Colonna A, Santamaria R. High Fat Diet Induces Liver Steatosis and Early Dysregulation of Iron Metabolism in Rats. PLoS ONE. 2013;8:1-11.

26. Ma Y, Smith CE, Lai C-Q, Irvin MR, Parnell LD, Lee Y-C, Pham LD, Aslibekyan S, Claas SA, Tsai MY, et al. The effects of omega-3 polyunsaturated fatty acids and genetic variants on methylation levels of the interleukin-6 gene promoter. Mol Nutr Food Res. 60:410-9.

27. Uribarri J, Castillo D, Dolores M, Maza DL, Pía M, Filip R, Gugliucci A, LuevanoContreras C, Macías-Cervantes MH, Bastos M, et al. Dietary Advanced Glycation End Products and Their Role in Health and Disease. Adv Nutr. 2015;6:461-73.

28. Bengmark S. Processed Foods, Dysbiosis, Systemic Inflammation, and Poor Health. :31.

29. Barroso WA, Victorino VJ, Jeremias IC, Petroni RC, Ariga SKK, Salles TA, Barbeiro DF, Lima TM de, Souza HP de. High-fat diet inhibits PGC-1 $\alpha$ suppressive effect on NFкB signaling in hepatocytes. Eur J Nutr. 2017;1-10.

30. Ayaka Ohtsu, Yui Shibutani, Kotomi Seno, Hisataka Iwata, Takehito Kuwayama, Koumei Shirasuna. Advanced glycation end products and lipopolysaccharides stimulate interleukin-6 secretion via the RAGE/TLR4-NF- $\kappa$ B-ROS pathways and resveratrol attenuates these inflammatory responses in mouse macrophages. Exp Ther Med. 2017;14:4363-70.

31. Yuan X, Zhao J, Qu W, Zhang Y, Jia B, Fan Z, He Q, Li J. Accumulation and effects of dietary advanced glycation end products on the gastrointestinal tract in rats. Int J Food Sci Technol [Internet]. [cited 2018 Jun 8];0. Available from: http://onlinelibrary.wiley.com/doi/abs/10.1111/ijfs.13817

32. Kolesnik B, Heine CL, Schmidt R, Schmidt K, Mayer B, Gorren ACF. Aerobic nitric oxide-induced thiol nitrosation in the presence and absence of magnesium cations. Free Radic Biol Med. 2014;76:286-98. 
33. Julia C, Galan P, Touvier M, Meunier N, Papet I, Sapin V, Cano N, Faure P, Hercberg S, Kesse-Guyot E. Antioxidant Status and the Risk of Elevated C-Reactive Protein 12 Years Later. Ann Nutr Metab. 2014;65:289-98.

34. Bastide N, Dartois L, Dyevre V, Dossus L, Fagherazzi G, Serafini M, Boutron-Ruault MC. Dietary antioxidant capacity and all-cause and cause-specific mortality in the E3N/EPIC cohort study. Eur J Nutr. 2017;56:1233-43.

35. Selby-Pham SNB, Cottrell JJ, Dunshea FR, Ng K, Bennett LE, Howell KS. Dietary Phytochemicals Promote Health by Enhancing Antioxidant Defence in a Pig Model. Nutrients [Internet]. 2017 [cited 2018 Jun 3];9. Available from: https://www.ncbi.nlm.nih.gov/pmc/articles/PMC5537872/

36. Siriwardhana N, Kalupahana NS, Cekanova M, LeMieux M, Greer B, Moustaid-Moussa $\mathrm{N}$. Modulation of adipose tissue inflammation by bioactive food compounds. J Nutr Biochem. 2013;24:613-23.

37. Endo J, Arita M. Cardioprotective mechanism of omega-3 polyunsaturated fatty acids. J Cardiol. 2016;67:22-7.

38. Casas R, Estruch R, Sacanella E. The Protective Effects of Extra Virgin Olive Oil on Immune-mediated Inflammatory Responses. Endocr Metab Immune Disord Drug Targets. 2018;18:23-35.

39. Sweazea KL, Johnston CS, Ricklefs KD, Petersen KN. Almond supplementation in the absence of dietary advice significantly reduces C-reactive protein in subjects with type 2 diabetes. J Funct Foods. 2014;10:252-9.

40. Maiorino MI, Bellastella G, Petrizzo M, Scappaticcio L, Giugliano D, Esposito K. Antiinflammatory Effect of Mediterranean Diet in Type 2 Diabetes Is Durable: 8-Year Followup of a Controlled Trial. Diabetes Care. 2016;39:e44-5.

41. Tyrovolas S, Haro JM, Foscolou A, Tyrovola D, Mariolis A, Bountziouka V, Piscopo S, Valacchi G, Anastasiou F, Gotsis E, et al. Anti-Inflammatory Nutrition and Successful Ageing in Elderly Individuals: The Multinational MEDIS Study. Gerontology. 2018;64:310.

42. Griffiths K, Aggarwal B, Singh R, Buttar H, Wilson D, De Meester F, Griffiths K, Aggarwal BB, Singh RB, Buttar HS, et al. Food Antioxidants and Their AntiInflammatory Properties: A Potential Role in Cardiovascular Diseases and Cancer Prevention. Diseases. 2016;4:28.

43. Jaacks LM, Sher S, De Staercke C, Porkert M, Alexander WR, Jones DP, Vaccarino V, Ziegler TR, Quyyumi AA. Pilot randomized controlled trial of a Mediterranean diet or diet supplemented with fish oil, walnuts, and grape juice in overweight or obese US adults. BMC Nutr. 2018;4:26. 
44. Jayarathne S, Koboziev I, Park O-H, Oldewage-Theron W, Shen C-L, Moustaid-Moussa N. Anti-Inflammatory and Anti-Obesity Properties of Food Bioactive Components: Effects on Adipose Tissue. Prev Nutr Food Sci. 2017;22:251-62.

45. Shivappa N, Steck SE, Hurley TG, Hussey JR, Hébert JR. Designing and developing a literature-derived population-based dietary inflammatory index. Public Health Nutr. 2014;17:1689-96.

46. Astrup A, Bügel S. Overfed but undernourished: recognizing nutritional inadequacies/deficiencies in patients with overweight or obesity. Int J Obes. 2019;43:219.

47. sal E, Yenicesu I, Celik N, Pasaoglu H, Celik B, Pasaoglu OT, Kaya Z, Kocak U, Camurdan O, Bideci A, et al. Relationship between obesity and iron deficiency anemia: is there a role of hepcidin? Hematology. 2018;1-7.

48. Edison ES, Bajel A, Chandy M. Iron homeostasis: new players, newer insights. Eur J Haematol. 2008;81:411-24.

49. Oliveira F, Rocha S, Fernandes R. Iron Metabolism: From Health to Disease. J Clin Lab Anal. 2014;28:210-8.

50. Greminger AR, Lee DL, Shrager P, Mayer-Pröschel M. Gestational Iron Deficiency Differentially Alters the Structure and Function of White and Gray Matter Brain Regions of Developing Rats. J Nutr. 2014;144:1058-66.

51. Amin SB, Orlando M, Wang H. Latent Iron Deficiency In Utero Is Associated with Abnormal Auditory Neural Myelination in \$35 Weeks Gestational Age Infants. J Pediatr. 2013;163:1267-71.

52. East P, Delker E, Lozoff B, Delva J, Castillo M, Gahagan S. Associations Among Infant Iron Deficiency, Childhood Emotion and Attention Regulation, and Adolescent Problem Behaviors. Child Dev. 2018;89:593-608.

53. Scott SP, Murray-Kolb LE. Iron Status Is Associated with Performance on Executive Functioning Tasks in Nonanemic Young Women. J Nutr. 2016;146:30-7.

54. Clark SF. Iron deficiency anemia: diagnosis and management: Curr Opin Gastroenterol. 2009;25:122-8.

55. Brigham EP, McCormack MC, Takemoto CM, Matsui EC. Iron Status is Associated with Asthma and Lung Function in US Women. PLoS One San Franc. 2015;10:e0117545.

56. Legrand D. Overview of Lactoferrin as a Natural Immune Modulator. J Pediatr. 2016;173:S10-5. 
57. Kawakami H, Park H, Park S, Kuwata H, Shephard RJ, Aoyagi Y. Effects of entericcoated lactoferrin supplementation on the immune function of elderly individuals: A randomised, double-blind, placebo-controlled trial. Int Dairy J. 2015;47:79-85.

58. Jaeggi T, Kortman GAM, Moretti D, Chassard C, Holding P, Dostal A, Boekhorst J, Timmerman HM, Swinkels DW, Tjalsma H, et al. Iron fortification adversely affects the gut microbiome, increases pathogen abundance and induces intestinal inflammation in Kenyan infants. Gut. 2015;64:731-42.

59. Das I, Saha K, Mukhopadhyay D, Roy S, Raychaudhuri G, Chatterjee M, Mitra PK. Impact of iron deficiency anemia on cell-mediated and humoral immunity in children: A case control study. J Nat Sci Biol Med. 2014;5:158-63.

60. Paganini D, Uyoga MA, Zimmermann MB. Iron Fortification of Foods for Infants and Children in Low-Income Countries: Effects on the Gut Microbiome, Gut Inflammation, and Diarrhea. Nutrients. 2016;8:494.

61. Matsumoto M, Hagio M, Katsumata M, Noguchi T. Combined Heme Iron Supplementation and Nutritional Counseling Improves Sports Anemia in Female Athletes. $2015 ; 8$.

62. Houston BL, Hurrie D, Graham J, Perija B, Rimmer E, Rabbani R, Bernstein CN, Turgeon AF, Fergusson DA, Houston DS, et al. Efficacy of iron supplementation on fatigue and physical capacity in non-anaemic iron-deficient adults: a systematic review of randomised controlled trials. BMJ Open. 2018;8:e019240.

63. Martin N, Beck K, Conlon C, Smeele R, Mugridge O, McClung J, von Hurst P. Iron status and associations with aerobic performance and stress fracture risk during initial military training. J Sci Med Sport. 2017;20:S164-5.

64. Pasricha S-R, Low M, Thompson J, Farrell A, De-Regil L-M. Iron Supplementation Benefits Physical Performance in Women of Reproductive Age: A Systematic Review and Meta-Analysis. J Nutr. 2014;144:906-14.

65. Mielgo-Ayuso J, Zourdos MC, Calleja-González J, Urdampilleta A, Ostojic S. Iron supplementation prevents a decline in iron stores and enhances strength performance in elite female volleyball players during the competitive season. Appl Physiol Nutr Metab. 2015;40:615-22.

66. Institute of Medicine (US) Panel on Micronutrients. Dietary Reference Intakes for Vitamin A, Vitamin K, Arsenic, Boron, Chromium, Copper, Iodine, Iron, Manganese, Molybdenum, Nickel, Silicon, Vanadium, and Zinc [Internet]. Washington (DC): National Academies Press (US); 2001 [cited 2018 Oct 25]. Available from:

http://www.ncbi.nlm.nih.gov/books/NBK222310/ 
67. Armah SM, Carriquiry AL, Reddy MB. Total Iron Bioavailability from the US Diet Is Lower Than the Current Estimate. J Nutr. 2015;145:2617-21.

68. Young I, Parker HM, Rangan A, Prvan T, Cook RL, Donges CE, Steinbeck KS, O’Dwyer NJ, Cheng HL, Franklin JL, et al. Association between Haem and Non-Haem Iron Intake and Serum Ferritin in Healthy Young Women. Nutrients [Internet]. 2018 [cited 2018 Sep 8];10. Available from: https://www.ncbi.nlm.nih.gov/pmc/articles/PMC5793309/

69. Barkley JS, Wheeler KS, Pachón H. Anaemia prevalence may be reduced among countries that fortify flour. Br J Nutr Camb. 2015;114:265-73.

70. Nam T-S, Shim JY, Kim B-J, Rah SY, Park K-H, Kim S-Y, Mun E-G, Jeong Y-J, Han M$\mathrm{K}$, Cha Y-S, et al. Clinical Study on the Iron Absorption from Heme-Iron Polypeptide and Nonheme-Iron. :7.

71. Ma Y, Okazaki Y, Glass J. A fluorescent metal-sensor study provides evidence for iron transport by transcytosis in the intestinal epithelial cells., A fluorescent metal-sensor study provides evidence for iron transport by transcytosis in the intestinal epithelial cells. J Clin Biochem Nutr J Clin Biochem Nutr. 2018;62, 62:49, 49-55.

72. Staroń R, Lipiński P, Lenartowicz M, Bednarz A, Gajowiak A, Smuda E, Krzeptowski W, Pieszka M, Korolonek T, Hamza I, et al. Dietary hemoglobin rescues young piglets from severe iron deficiency anemia: Duodenal expression profile of genes involved in heme iron absorption. PLoS One San Franc. 2017;12:e0181117.

73. Mónica A, Lautaro B, Fernando P, Miguel A. Calcium and zinc decrease intracellular iron by decreasing transport during iron repletion in an in vitro model. Eur J Nutr [Internet]. 2017 [cited 2018 Aug 8]; Available from: http://link.springer.com/10.1007/s00394-017$1535-7$

74. Duck KA, Connor JR. Iron uptake and transport across physiological barriers. Biometals. 2016;29:573-91.

75. Prentice AM. Clinical Implications of New Insights into Hepcidin-Mediated Regulation of Iron Absorption and Metabolism. Ann Nutr Metab. 2017;71:40-8.

76. Śliwińska A, Luty J, Aleksandrowicz-Wrona E, Małgorzewicz S. Iron status and dietary iron intake in vegetarians. Adv Clin Exp Med Off Organ Wroclaw Med Univ [Internet]. 2018 [cited 2018 Oct 25]; Available from: http://europepmc.org/abstract/med/30062867

77. Ghatpande NS, Apte PP, Naik SS, Kulkarni PP. Fruit and Vegetable Consumption and Their Association With the Indicators of Iron and Inflammation Status Among Adolescent Girls. J Am Coll Nutr. 2018;0:1-9. 
78. Bansal PG, Toteja GS, Bhatia N, Vikram NK, Siddhu A. Impact of weekly iron folic acid supplementation with and without vitamin B12 on anaemic adolescent girls: a randomised clinical trial. Eur J Clin Nutr. 2016;70:730-7.

79. Napolitano M, Dolce A, Celenza G, Grandone E, Perilli MG, Siragusa S, Carta G, Orecchioni A, Mariani G. Iron-dependent erythropoiesis in women with excessive menstrual blood losses and women with normal menses. Ann Hematol. 2014;93:557-63.

80. Petry N, Olofin I, Hurrell RF, Boy E, Wirth JP, Moursi M, Donahue Angel M, Rohner F. The Proportion of Anemia Associated with Iron Deficiency in Low, Medium, and High Human Development Index Countries: A Systematic Analysis of National Surveys. Nutrients. 2016;8:693.

81. Kassebaum NJ, Jasrasaria R, Naghavi M, Wulf SK, Johns N, Lozano R, Regan M, Weatherall D, Chou DP, Eisele TP, et al. A systematic analysis of global anemia burden from 1990 to 2010. Blood. 2014;123:615-24.

82. Goetze O, Schmitt J, Spliethoff K, Theurl I, Weiss G, Swinkels DW, Tjalsma H, Maggiorini M, Krayenbühl P, Rau M, et al. Adaptation of iron transport and metabolism to acute high-altitude hypoxia in mountaineers. Hepatology. 2013;58:2153-62.

83. Kuhrt D, Wojchowski DM. Emerging EPO and EPO receptor regulators and signal transducers. Blood. 2015;125:3536-41.

84. Kautz L, Jung G, Valore EV, Rivella S, Nemeth E, Ganz T. IDENTIFICATION OF ERYTHROFERRONE AS AN ERYTHROID REGULATOR OF IRON METABOLISM. Nat Genet. 2014;46:678-84.

85. Coffey R, Ganz T. Erythroferrone: An Erythroid Regulator of Hepcidin and Iron Metabolism. HemaSphere. 2018;2:e35.

86. Giardiasis as a re-emerging infectious disease and its zoonotic potential. Int J Parasitol. 2000;30:1259-67.

87. Hussein EM, Zaki WM, Ahmed SA, Almatary AM, Nemr NI, Hussein AM. Predominance of Giardia lamblia assemblage A among iron deficiency anaemic pre-school Egyptian children. Parasitol Res. 2016;115:1537-45.

88. Beydoun MA, Dore GA, Canas JA, Beydoun HA, Zonderman AB. Helicobacter pylori Seropositivity's Association with Markers of Iron, 1-Carbon Metabolism, and Antioxidant Status among US Adults: A Structural Equations Modeling Approach. PLoS ONE [Internet]. 2015 [cited 2018 Aug 23];10. Available from: https://www.ncbi.nlm.nih.gov/pmc/articles/PMC4376857/

89. Sato Y, Yoneyama O, Azumaya M, Takeuchi M, Sasaki S, Yokoyama J, Shioji K, Kawauchi Y, Hashimoto S, Nishigaki Y, et al. The Relationship Between Iron Deficiency 
in Patients with Helicobacter Pylori-Infected Nodular Gastritis and the Serum Prohepcidin Level. Helicobacter. 2015;20:11-8.

90. Mwafy SN, Afana WM. Hematological parameters, serum iron and vitamin B 12 levels in hospitalized Palestinian adult patients infected with Helicobacter pylori : a case-control study. Hematol Transfus Cell Ther. 2018;40:160-5.

91. Sangkhae V, Nemeth E. Regulation of the Iron Homeostatic Hormone Hepcidin. Adv Nutr. 2017;8:126-36.

92. Camaschella C, Pagani A. Advances in understanding iron metabolism and its crosstalk with erythropoiesis. Br J Haematol [Internet]. [cited 2018 Jul 6];0. Available from: http://onlinelibrary.wiley.com/doi/abs/10.1111/bjh.15403

93. Bergamaschi G, Di Sabatino A, Pasini A, Ubezio C, Costanzo F, Grataroli D, Masotti M, Alvisi C, Corazza GR. Intestinal expression of genes implicated in iron absorption and their regulation by hepcidin. Clin Nutr. 2017;36:1427-33.

94. Gulec S, Anderson GJ, Collins JF. Mechanistic and regulatory aspects of intestinal iron absorption. Am J Physiol - Gastrointest Liver Physiol. 2014;307:G397-409.

95. Monfort-Pires M, Ferreira SRG. Modification in a single meal is sufficient to provoke benefits in inflammatory responses of individuals at low-to-moderate cardiometabolic risk. Clin Nutr Edinb Scotl. 2016;35:1242-50.

96. Kien CL, Matthews DE, Poynter ME, Bunn JY, Fukagawa NK, Crain KI, Ebenstein DB, Tarleton EK, Stevens RD, Koves TR, et al. Increased palmitate intake: higher acylcarnitine concentrations without impaired progression of $\beta$-oxidation. J Lipid Res. 2015;56:1795-807.

97. Dumas JA, Bunn JY, Nickerson J, Crain KI, Ebenstein DB, Tarleton EK, Makarewicz J, Poynter ME, Kien CL. Dietary saturated fat and monounsaturated fat have reversible effects on brain function and the secretion of pro-inflammatory cytokines in young women. Metabolism. 2016;65:1582-8.

98. Martínez-Micaelo N, González-Abuín N, Pinent M, Ardévol A, Blay M. Dietary fatty acid composition is sensed by the NLRP3 inflammasome: omega-3 fatty acid (DHA) prevents NLRP3 activation in human macrophages. Food Funct. 2016;7:3480-7.

99. Baril-Gravel L, Labonté M-E, Couture P, Vohl M-C, Charest A, Guay V, Jenkins DA, Connelly PW, West S, Kris-Etherton PM, et al. Docosahexaenoic acid-enriched canola oil increases adiponectin concentrations: A randomized crossover controlled intervention trial. Nutr Metab Cardiovasc Dis. 2015;25:52-9.

100. Dokmanović SK, Kolovrat K, Laškaj R, Jukić V, Vrkić N, Begovac J. Effect of Extra Virgin Olive Oil on Biomarkers of Inflammation in HIV-Infected Patients: A Randomized, 
Crossover, Controlled Clinical Trial. Med Sci Monit Int Med J Exp Clin Res. 2015;21:2406-13.

101. Collins B, Hoffman J, Martinez K, Grace M, Lila MA, Cockrell C, Nadimpalli A, Chang E, Chuang C-C, Zhong W, et al. A polyphenol-rich fraction obtained from table grapes decreases adiposity, insulin resistance and markers of inflammation and impacts gut microbiota in high-fat-fed mice. J Nutr Biochem. 2016;31:150-65.

102. Cassidy A, Rogers G, Peterson JJ, Dwyer JT, Lin H, Jacques PF. Higher dietary anthocyanin and flavonol intakes are associated with anti-inflammatory effects in a population of US adults. Am J Clin Nutr. 2015;102:172-81.

103. Dwyer JT, Peterson J. Tea and flavonoids: where we are, where to go next. Am J Clin Nutr. 2013;98:1611S-1618S.

104. Lee M, McGeer EG, McGeer PL. Quercetin, not caffeine, is a major neuroprotective component in coffee. Neurobiol Aging. 2016;46:113-23.

105. Hwang SJ, Kim Y-W, Park Y, Lee H-J, Kim K-W. Anti-inflammatory effects of chlorogenic acid in lipopolysaccharide-stimulated RAW 264.7 cells. Inflamm Res. 2014;63:81-90.

106. Jung S, Kim MH, Park JH, Jeong Y, Ko KS. Cellular Antioxidant and Anti-Inflammatory Effects of Coffee Extracts with Different Roasting Levels. J Med Food. 2017;20:626-35.

107. Choi S, Jung S, Ko KS. Effects of Coffee Extracts with Different Roasting Degrees on Antioxidant and Anti-Inflammatory Systems in Mice. Nutrients [Internet]. 2018 [cited 2018 Oct 18];10. Available from: https://www.ncbi.nlm.nih.gov/pmc/articles/PMC5872781/

108. Katayama M, Donai K, Sakakibara H, Ohtomo Y, Miyagawa M, Kuroda K, Kodama H, Suzuki K, Kasai N, Nishimori K, et al. Coffee consumption delays the hepatitis and suppresses the inflammation related gene expression in the Long-Evans Cinnamon rat. Clin Nutr. 2014;33:302-10.

109. Yamashita K, Yatsuya H, Muramatsu T, Toyoshima H, Murohara T, Tamakoshi K. Association of coffee consumption with serum adiponectin, leptin, inflammation and metabolic markers in Japanese workers: a cross-sectional study. Nutr Diabetes. 2012;2:e33.

110. Shahmohammadi HA, Hosseini SA, Hajiani E, Malehi AS, Alipour M. Effects of Green Coffee Bean Extract Supplementation on Patients with Non-Alcoholic Fatty Liver Disease: A Randomized Clinical Trial. Hepat Mon [Internet]. 2017 [cited 2018 Oct 15];17. Available from: http://hepatmon.com/en/articles/12299.html 
111. Loftfield E, Shiels MS, Graubard BI, Katki HA, Chaturvedi AK, Trabert B, Pinto LA, Kemp TJ, Shebl FM, Mayne ST, et al. Associations of coffee drinking with systemic immune and inflammatory markers. Cancer Epidemiol Biomark Prev Publ Am Assoc Cancer Res Cosponsored Am Soc Prev Oncol. 2015;24:1052-60.

112. Hayat K, Iqbal H, Malik U, Bilal U, Mushtaq S. Tea and Its Consumption: Benefits and Risks. Crit Rev Food Sci Nutr. 2015;55:939-54.

113. Ramadan G, El-Beih NM, Talaat RM, El-Ghffar EAA. Anti-inflammatory activity of green versus black tea aqueous extract in a rat model of human rheumatoid arthritis. Int $\mathbf{J}$ Rheum Dis. 2017;20:203-13.

114. Mukherjee S, Siddiqui MA, Dayal S, Ayoub YZ, Malathi K. Epigallocatechin-3-gallate suppresses proinflammatory cytokines and chemokines induced by Toll-like receptor 9 agonists in prostate cancer cells. J Inflamm Res. 2014;7:89.

115. Sakamoto Y, Kanatsu J, Toh M, Naka A, Kondo K, Iida K. The Dietary Isoflavone Daidzein Reduces Expression of Pro-Inflammatory Genes through PPAR $\alpha / \gamma$ and JNK Pathways in Adipocyte and Macrophage Co-Cultures. PLoS ONE [Internet]. 2016 [cited 2018 Jan 26]; 11. Available from: https://www.ncbi.nlm.nih.gov/pmc/articles/PMC4763373/

116. Ferguson JF, Ryan MF, Gibney ER, Brennan L, Roche HM, Reilly MP. Dietary isoflavone intake is associated with evoked responses to inflammatory cardiometabolic stimuli and improved glucose homeostasis in healthy volunteers. Nutr Metab Cardiovasc Dis. 2014;24:996-1003.

117. Charles C, Yuskavage J, Carlson O, John M, Tagalicud AS, Maggio M, Muller DC, Egan J, Basaria S. Effects of high-dose isoflavones on metabolic and inflammatory markers in healthy postmenopausal women: Menopause. 2009;16:395-400.

118. Amanat S, Eftekhari MH, Fararouei M, Bagheri Lankarani K, Massoumi SJ. Genistein supplementation improves insulin resistance and inflammatory state in non-alcoholic fatty liver patients: A randomized, controlled trial. Clin Nutr Edinb Scotl. 2017;

119. Mangano KM, Hutchins-Wiese HL, Kenny AM, Walsh SJ, Abourizk RH, Bruno RS, Lipcius R, Fall P, Kleppinger A, Kenyon-Pesce L, et al. Soy proteins and isoflavones reduce interleukin- 6 but not serum lipids in older women: a randomized controlled trial. Nutr Res. 2013;33:1026-33.

120. Lin Q, Mathieu O, Tompkins TA, Buckley ND, Green-Johnson JM. Modulation of the $\mathrm{TNF} \alpha$-induced gene expression profile of intestinal epithelial cells by soy fermented with lactic acid bacteria. J Funct Foods. 2016;23:400-11.

121. Filiberto AC, Mumford SL, Pollack AZ, Zhang C, Yeung EH, Perkins NJ, WactawskiWende J, Schisterman EF. Habitual Dietary Isoflavone Intake Is Associated with 
Decreased C-Reactive Protein Concentrations among Healthy Premenopausal Women. J Nutr. 2013;143:900-6.

122. Nadadur M, Stanczyk FZ, Chiu-Chen Tseng, Lila Kim, Wu AH. The Effect of Reduced Dietary Fat and Soy Supplementation on Circulating Adipocytokines in Postmenopausal Women: A Randomized Controlled 2-Month Trial. Nutr Cancer. 2016;68:554-9.

123. Cediel G, Reyes M, da Costa Louzada ML, Martinez Steele E, Monteiro CA, Corvalán C, Uauy R. Ultra-processed foods and added sugars in the Chilean diet (2010). Public Health Nutr. 2018;21:125-33.

124. Christ A, Günther P, Lauterbach MAR, Duewell P, Biswas D, Pelka K, Scholz CJ, Oosting M, Haendler K, Baßler K, et al. Western Diet Triggers NLRP3-Dependent Innate Immune Reprogramming. Cell. 2018;172:162-175.e14.

125. Chevre R, Silvestre-Roig C, Soehnlein O. Nutritional Modulation of Innate Immunity: The Fat-Bile-Gut Connection. Trends Endocrinol Metab. 2018;29:686-98.

126. Richards JL, Yap YA, McLeod KH, Mackay CR, Mariño E. Dietary metabolites and the gut microbiota: an alternative approach to control inflammatory and autoimmune diseases [Internet]. Clinical \& Translational Immunology. 2016 [cited 2019 Jun 18]. Available from: https://onlinelibrary.wiley.com/doi/abs/10.1038/cti.2016.29

127. Statovci D, Aguilera M, MacSharry J, Melgar S. The Impact of Western Diet and Nutrients on the Microbiota and Immune Response at Mucosal Interfaces. Front Immunol [Internet]. 2017 [cited 2019 Jun 18];8. Available from:

https://www.frontiersin.org/articles/10.3389/fimmu.2017.00838/full

128. Jena PK, Sheng L, Liu H-X, Kalanetra KM, Mirsoian A, Murphy WJ, French SW, Krishnan VV, Mills DA, Wan Y-JY. Western Diet-Induced Dysbiosis in Farnesoid X Receptor Knockout Mice Causes Persistent Hepatic Inflammation after Antibiotic Treatment. Am J Pathol. 2017;187:1800-13.

129. Rutkowsky JM, Lee LL, Puchowicz M, Golub MS, Befroy DE, Wilson DW, Anderson S, Cline G, Bini J, Borkowski K, et al. Reduced cognitive function, increased blood-brainbarrier transport and inflammatory responses, and altered brain metabolites in LDLr $-/$-and C57BL/6 mice fed a western diet. PLoS ONE [Internet]. 2018 [cited 2019 Jun 18];13. Available from: https://www.ncbi.nlm.nih.gov/pmc/articles/PMC5812615/

130. Rodríguez LA, Madsen KA, Cotterman C, Lustig RH. Added sugar intake and metabolic syndrome in US adolescents: cross-sectional analysis of the National Health and Nutrition Examination Survey 2005-2012. Public Health Nutr. 2016;19:2424-34.

131. Sadowska J, Bruszkowska M. Comparing the effects of sucrose and high-fructose corn syrup on lipid metabolism and the risk of cardiovascular disease in male rats. Acta Sci Pol Technol Aliment. 2017;16:231-40. 
132. Ma X, Lin L, Yue J, Pradhan G, Qin G, Minze LJ, Wu H, Sheikh-Hamad D, Smith CW, Sun Y. Ghrelin receptor regulates HFCS-induced adipose inflammation and insulin resistance. Nutr Diabetes. 2013;3:e99.

133. Vreman RA, Goodell AJ, Rodriguez LA, Porco TC, Lustig RH, Kahn JG. Health and economic benefits of reducing sugar intake in the USA, including effects via non-alcoholic fatty liver disease: a microsimulation model. BMJ Open. 2017;7:e013543.

134. Hu FB. Resolved: there is sufficient scientific evidence that decreasing sugar-sweetened beverage consumption will reduce the prevalence of obesity and obesity-related diseases. Obes Rev. 2013;14:606-19.

135. O'Connor L, Imamura F, Brage S, Griffin SJ, Wareham NJ, Forouhi NG. Intakes and sources of dietary sugars and their association with metabolic and inflammatory markers. Clin Nutr Edinb Scotl. 2018;37:1313-22.

136. Yu Z, Ley SH, Sun Q, Hu FB, Malik VS. Cross-sectional association between sugarsweetened beverage intake and cardiometabolic biomarkers in US women. Br J Nutr. 2018;119:570-80.

137. Bartone DC, McKeown NM, Morrish KR, Smith CE, Lai C-Q, Parnell LD, Ordovas JM. Sugar-Sweetened Beverage Intake as a Modulator of Genetic Associations for Chronic Inflammation Relevant to Cardiovascular Disease. FASEB J [Internet]. 2017 [cited 2019 Jun 18]; Available from:

https://www.fasebj.org/doi/abs/10.1096/fasebj.31.1_supplement.644.22

138. Koebnick C, Black MH, Wu J, Shu Y-H, MacKay AW, Watanabe RM, Buchanan TA, Xiang AH. A diet high in sugar-sweetened beverage and low in fruits and vegetables is associated with adiposity and a pro-inflammatory adipokine profile. $\mathrm{Br} \mathrm{J}$ Nutr. 2018;120:1230-9.

139. De Stefanis D, Mastrocola R, Nigro D, Costelli P, Aragno M. Effects of chronic sugar consumption on lipid accumulation and autophagy in the skeletal muscle. Eur J Nutr. 2017;56:363-73.

140. Kovačević S, Nestorov J, Matić G, Elaković I. Fructose-enriched diet induces inflammation and reduces antioxidative defense in visceral adipose tissue of young female rats. Eur J Nutr. 2017;56:151-60.

141. Raatz SK, Johnson LK, Picklo MJ. Consumption of Honey, Sucrose, and High-Fructose Corn Syrup Produces Similar Metabolic Effects in Glucose-Tolerant and -Intolerant Individuals. J Nutr. 2015;145:2265-72.

142. Aeberli I, Gerber PA, Hochuli M, Kohler S, Haile SR, Gouni-Berthold I, Berthold HK, Spinas GA, Berneis K. Low to moderate sugar-sweetened beverage consumption impairs 
glucose and lipid metabolism and promotes inflammation in healthy young men: a randomized controlled trial. Am J Clin Nutr. 2011;94:479-85.

143. Jin R, Welsh JA, Le N-A, Holzberg J, Sharma P, Martin DR, Vos MB. Dietary Fructose Reduction Improves Markers of Cardiovascular Disease Risk in Hispanic-American Adolescents with NAFLD. Nutrients. 2014;6:3187-201.

144. Delgado-Andrade C, Fogliano V. Dietary Advanced Glycosylation End-Products (dAGEs) and Melanoidins Formed through the Maillard Reaction: Physiological Consequences of their Intake. Annu Rev Food Sci Technol. 2018;9:271-91.

145. Snelson M, Coughlan MT. Dietary Advanced Glycation End Products: Digestion, Metabolism and Modulation of Gut Microbial Ecology. Nutrients. 2019;11:215.

146. Takeuchi M, Takino J, Furuno S, Shirai H, Kawakami M, Muramatsu M, Kobayashi Y, Yamagishi S. Assessment of the Concentrations of Various Advanced Glycation EndProducts in Beverages and Foods That Are Commonly Consumed in Japan. Hudson BI, editor. PLOS ONE. 2015; 10:e0118652.

147. al SU et. Free Maillard Reaction Products in Milk Reflect Nutritional Intake of Glycated Proteins and Can Be Used to Distinguish "Organic" and "Conventionall... - PubMed NCBI [Internet]. [cited 2019 Apr 13]. Available from: http://www.ncbi.nlm.nih.gov/pubmed/27213835

148. Clarke RE, Dordevic AL, Tan SM, Ryan L, Coughlan MT. Dietary Advanced Glycation End Products and Risk Factors for Chronic Disease: A Systematic Review of Randomised Controlled Trials. Nutrients. 2016;8:125.

149. Di Pino A, Currenti W, Urbano F, Scicali R, Piro S, Purrello F, Rabuazzo AM. High intake of dietary advanced glycation end-products is associated with increased arterial stiffness and inflammation in subjects with type 2 diabetes. Nutr Metab Cardiovasc Dis. 2017;27:978-84.

150. Di Pino A, Currenti W, Urbano F, Mantegna C, Purrazzo G, Piro S, Purrello F, Rabuazzo AM. Low advanced glycation end product diet improves the lipid and inflammatory profiles of prediabetic subjects. J Clin Lipidol. 2016;10:1098-108.

151. Luévano-Contreras C, Garay-Sevilla MaE, Wrobel K, Malacara JM, Wrobel K. Dietary advanced glycation end products restriction diminishes inflammation markers and oxidative stress in patients with type 2 diabetes mellitus. J Clin Biochem Nutr. 2013;52:22-6.

152. Elmhiri G, Mahmood DFD, Niquet-Leridon C, Jacolot P, Firmin S, Guigand L, Tessier FJ, Larcher T, Abdennebi-Najar L. Formula-derived advanced glycation end products are involved in the development of long-term inflammation and oxidative stress in kidney of IUGR piglets. Mol Nutr Food Res. 2015;59:939-47. 
153. Nass N, Bayreuther K, Simm A. Systemic activation of NF- $\kappa B$ driven luciferase activity in transgenic mice fed advanced glycation end products modified albumin. Glycoconj J. 2017;34:157-61.

154. Yeh W-J. Long-term administration of advanced glycation end-product stimulates the activation of NLRP3 inflammasome and sparking the development of renal injury. J Nutr Biochem. 2017;39:68-76.

155. Tabung FK, Smith-Warner SA, Chavarro JE, Wu K, Fuchs CS, Hu FB, Chan AT, Willett WC, Giovannucci EL. Development and Validation of an Empirical Dietary Inflammatory Index123. J Nutr. 2016;146:1560-70.

156. Tabung FK, Smith-Warner SA, Chavarro JE, Fung TT, Hu FB, Willett WC, Giovannucci EL. An Empirical Dietary Inflammatory Pattern Score Enhances Prediction of Circulating Inflammatory Biomarkers in Adults. J Nutr. 2017;147:1567-77.

157. Tabung FK, Steck SE, Ma Y, Liese AD, Zhang J, Caan B, Hou L, Johnson KC, MossavarRahmani Y, Shivappa N, et al. The association between dietary inflammatory index and risk of colorectal cancer among postmenopausal women: results from the Women's Health Initiative. Cancer Causes Control. 2015;26:399-408.

158. Fowler ME, Akinyemiju TF. Meta-analysis of the association between dietary inflammatory index (DII) and cancer outcomes. Int J Cancer. 2017;141:2215-27.

159. Farhangi MA, Najafi M. Dietary inflammatory index: a potent association with cardiovascular risk factors among patients candidate for coronary artery bypass grafting (CABG) surgery. Nutr J. 2018;17:20.

160. Shivappa N, Godos J, Hébert JR, Wirth MD, Piuri G, Speciani AF, Grosso G. Dietary Inflammatory Index and Cardiovascular Risk and Mortality-A Meta-Analysis. Nutrients [Internet]. 2018 [cited 2018 Aug 8];10. Available from: https://www.ncbi.nlm.nih.gov/pmc/articles/PMC5852776/

161. Shivappa N, Hébert JR, Rosato V, Montella M, Serraino D, Vecchia CL. Association between the dietary inflammatory index and breast cancer in a large Italian case-control study. Mol Nutr Food Res. 2017;61:1600500.

162. Turner-McGrievy GM, Wirth MD, Shivappa N, Dunn CG, Crimarco A, Hurley TG, West DS, Hussey JR, Hébert JR. Impact of a 12-month Inflammation Management Intervention on the Dietary Inflammatory Index, inflammation, and lipids. Clin Nutr ESPEN [Internet]. 2019 [cited 2019 Mar 16]; Available from: http://www.sciencedirect.com/science/article/pii/S2405457718306168

163. Khan S, Wirth M, Ortaglia A, Alvarado C, Shivappa N, Hurley T, Hebert J, Khan S, Wirth MD, Ortaglia A, et al. Design, Development and Construct Validation of the Children's Dietary Inflammatory Index. Nutrients. 2018;10:993. 
164. Shivappa N, Steck SE, Hurley TG, Hussey JR, Ma Y, Ockene IS, Tabung F, Hébert JR. A population-based dietary inflammatory index predicts levels of C-reactive protein in the Seasonal Variation of Blood Cholesterol Study (SEASONS). Public Health Nutr. 2014;17:1825-33.

165. Shivappa N, Wirth MD, Hurley TG, Hébert JR. Association between the dietary inflammatory index (DII) and telomere length and C-reactive protein from the National Health and Nutrition Examination Survey-1999-2002. Mol Nutr Food Res [Internet]. 2017 [cited 2019 Mar 16];61. Available from:

http://onlinelibrary.wiley.com/doi/abs/10.1002/mnfr.201600630

166. Tabung FK. Construct validation of the dietary inflammatory index among postmenopausal women. Ann Epidemiol. 2015;25:398-405.

167. Wirth MD, Shivappa N, Davis L, Hurley TG, Ortaglia A, Drayton R, Blair SN, Hébert JR. Construct Validation of the Dietary Inflammatory Index among African Americans. J Nutr Health Aging. 2017;21:487-91.

168. Wirth MD, Burch J, Shivappa N, Violanti JM, Burchfiel CM, Fekedulegn D, Andrew ME, Hartley TA, Miller DB, Mnatsakanova A, et al. Association of a Dietary Inflammatory Index With Inflammatory Indices and Metabolic Syndrome Among Police Officers: J Occup Environ Med. 2014;56:986-9.

169. Herter-aeberli I, Thankachan P, Bose B, Kurpad AV. Increased risk of iron deficiency and reduced iron absorption but no difference in zinc, vitamin A or B-vitamin status in obese women in India. Eur J Nutr Heidelb. 2016;55:2411-21.

170. Alam F, Memon AS, Fatima SS. Increased Body Mass Index may lead to Hyperferritinemia Irrespective of Body Iron Stores. Pak J Med Sci. 2015;31:1521-6.

171. Shekarriz R, Vaziri MM. Iron Profile and Inflammatory Status of Overweight and Obese Women in Sari, North of Iran. Int J Hematol-Oncol Stem Cell Res. 2017;11:108.

172. Aigner E, Feldman A, Datz C. Obesity as an Emerging Risk Factor for Iron Deficiency. Nutrients. 2014;6:3587-600.

173. Casper C, Chaturvedi S, Munshi N, Wong R, Qi M, Schaffer M, Bandekar R, Hall B, van de Velde H, Vermeulen J, et al. Analysis of Inflammatory and Anemia-Related Biomarkers in a Randomized, Double-Blind, Placebo-Controlled Study of Siltuximab (Anti-IL6 Monoclonal Antibody) in Patients With Multicentric Castleman Disease. Clin Cancer Res Off J Am Assoc Cancer Res. 2015;21:4294-304.

174. Becker C, Orozco M, Solomons NW, Schümann K. Iron metabolism in obesity: How interaction between homoeostatic mechanisms can interfere with their original purpose. Part I: Underlying homoeostatic mechanisms of energy storage and iron metabolisms and their interaction. J Trace Elem Med Biol. 2015;30:195-201. 
175. Arezes J, Jung G, Gabayan V, Valore E, Ruchala P, Gulig PA, Ganz T, Nemeth E, Bulut Y. Hepcidin-Induced Hypoferremia Is a Critical Host Defense Mechanism against the Siderophilic Bacterium Vibrio vulnificus. Cell Host Microbe. 2015;17:47-57.

176. Ross AC. Impact of chronic and acute inflammation on extra- and intracellular iron homeostasis. Am J Clin Nutr. 2017;106:1581S-1587S.

177. Andrews M, Soto N, Arredondo-Olguín M. Association between ferritin and hepcidin levels and inflammatory status in patients with type 2 diabetes mellitus and obesity. Nutrition. 2015;31:51-7.

178. Toubal A, Treuter E, Clément K, Venteclef N. Genomic and epigenomic regulation of adipose tissue inflammation in obesity. Trends Endocrinol Metab. 2013;24:625-34.

179. Citelli M, Fonte-Faria T, Nascimento-Silva V, Renovato-Martins M, Silva R, Luna AS, Vargas da Silva S, Barja-Fidalgo C. Obesity Promotes Alterations in Iron Recycling. Nutrients. 2015;7:335-48.

180. Mastrocola R, Aragno M, Alloatti G, Collino M, Penna C, Pagliaro P. Metaflammation: Tissue-Specific Alterations of the NLRP3 Inflammasome Platform in Metabolic Syndrome. Curr Med Chem. 2018;25:1294-310.

181. Larvie D, Doherty J, Armah S. Interrelationships Among Selenium, Iron Status and Inflammatory Biomarkers Among Young Adults (P24-021-19). Curr Dev Nutr [Internet]. 2019 [cited 2019 Jul 23];3. Available from:

http://academic.oup.com/cdn/article/3/Supplement_1/nzz044.P24-021-19/5517119

182. Doherty J, Armah S, Larvie D. Interrelationships Among Body Weight, Inflammation and Iron Status in Young Adults (P19-008-19). Curr Dev Nutr [Internet]. 2019 [cited 2019 Jul 23];3. Available from: http://academic.oup.com/cdn/article/3/Supplement_1/nzz049.P19$008-19 / 5518152$

183. R: The R Project for Statistical Computing [Internet]. [cited 2019 Oct 18]. Available from: https://www.r-project.org/

184. Ciesielska A, Kwiatkowska K. Modification of pro-inflammatory signaling by dietary components: The plasma membrane as a target. BioEssays News Rev Mol Cell Dev Biol. 2015;37:789-801.

185. Thomsen M, Nordestgaard BG. Myocardial Infarction and Ischemic Heart Disease in Overweight and Obesity With and Without Metabolic Syndrome. JAMA Intern Med. 2014;174:15-22.

186. Vuppalanchi R, Troutt JS, Konrad RJ, Ghabril M, Saxena R, Bell LN, Kowdley KV, Chalasani N. Serum hepcidin levels are associated with obesity but not liver disease. Obesity. 2014;22:836-41. 
187. Baumgartner J, Smuts CM, Aeberli I, Malan L, Tjalsma H, Zimmermann MB. Overweight impairs efficacy of iron supplementation in iron-deficient South African children: a randomized controlled intervention. Int J Obes. 2013;37:24-30.

188. Moreno-Navarrete JM, Moreno M, Puig J, Blasco G, Ortega F, Xifra G, Ricart W, Fernández-Real JM. Hepatic iron content is independently associated with serum hepcidin levels in subjects with obesity. Clin Nutr. 2017;36:1434-9.

189. Armah SM, Carriquiry A, Sullivan D, Cook JD, Reddy MB. A Complete Diet-Based Algorithm for Predicting Nonheme Iron Absorption in Adults. J Nutr. 2013;143:1136-40.

190. García-Meseguer MJ, Delicado-Soria A, Serrano-Urrea R. Fiber Patterns in Young Adults Living in Different Environments (USA, Spain, and Tunisia). Anthropometric and Lifestyle Characteristics. Nutrients. 2017;9:1030.

191. Wirth MD, Hébert JR, Shivappa N, Hand GA, Hurley TG, Drenowatz C, McMahon D, Shook RP, Blair SN. Anti-inflammatory Dietary Inflammatory Index scores are associated with healthier scores on other dietary indices. Nutr Res N Y N. 2016;36:214-9.

192. Muhammad HFL, van Baak MA, Mariman EC, Sulistyoningrum DC, Huriyati E, Lee YY, Wan Muda WAM. Dietary Inflammatory Index Score and Its Association with Body Weight, Blood Pressure, Lipid Profile, and Leptin in Indonesian Adults. Nutrients [Internet]. 2019 [cited 2019 Jun 13];11. Available from: https://www.ncbi.nlm.nih.gov/pmc/articles/PMC6356884/

193. Ruiz-Canela M, Zazpe I, Shivappa N, Hébert JR, Sánchez-Tainta A, Corella D, SalasSalvadó J, Fitó M, Lamuela-Raventós RM, Rekondo J, et al. Dietary inflammatory index and anthropometric measures of obesity in a population sample at high cardiovascular risk from the PREDIMED (PREvención con DIeta MEDiterránea) trial. Br J Nutr. 2015;113:984-95.

194. Kim Y, Chen J, Wirth MD, Shivappa N, Hebert JR. Lower Dietary Inflammatory Index Scores Are Associated with Lower Glycemic Index Scores among College Students. Nutrients [Internet]. 2018 [cited 2019 Jun 20];10. Available from: https://www.ncbi.nlm.nih.gov/pmc/articles/PMC5852758/

195. Wideman L, Oberlin DJ, Sönmez S, Labban J, Lemke MK, Apostolopoulos Y. Obesity indices are predictive of elevated C-reactive protein in long-haul truck drivers. Am J Ind Med. 59:665-75.

196. Zaki ME, El-Bassyouni HT, El-Gammal M, Kamal S. Indicators of the metabolic syndrome in obese adolescents. Arch Med Sci AMS. 2015;11:92-8.

197. Al-Odat AZ, Ahmad MN, Haddad FH. References of anthropometric indices of central obesity and metabolic syndrome in Jordanian men and women. Diabetes Metab Syndr Clin Res Rev. 2012;6:15-21. 
198. Bowman K, Atkins JL, Delgado J, Kos K, Kuchel GA, Ble A, Ferrucci L, Melzer D. Central adiposity and the overweight risk paradox in aging: follow-up of 130,473 UK Biobank participants. Am J Clin Nutr. 2017;106:130-5.

199. Boren JP, Veksler AE. Co-rumination and Immune Inflammatory Response in Healthy Young Adults: Associations with Interleukin-6 and C-Reactive Protein. Commun Res Rep [Internet]. 2017 [cited 2019 Jun 14]; Available from: http://www.tandfonline.com/doi/abs/10.1080/08824096.2017.1409619

200. Pourshahidi LK, Wallace JMW, Mulhern MS, Horigan G, Strain JJ, McSorley EM, Magee PJ, Bonham MP, Livingstone MBE. Indices of adiposity as predictors of cardiometabolic risk and inflammation in young adults. J Hum Nutr Diet. 2016;29:26-37.

201. Yudkin JS, Stehouwer CDA, Emeis JJ, Coppack SW. C-Reactive Protein in Healthy Subjects: Associations With Obesity, Insulin Resistance, and Endothelial Dysfunction. Arterioscler Thromb Vasc Biol [Internet]. 1999 [cited 2019 Jun 19]; Available from: https://www.ahajournals.org/doi/abs/10.1161/01.ATV.19.4.972

202. Visser M, Bouter LM, McQuillan GM, Wener MH, Harris TB. Elevated C-Reactive Protein Levels in Overweight and Obese Adults. JAMA. 1999;282:2131-5.

203. Bodén S, Wennberg M, Guelpen BV, Johansson I, Lindahl B, Andersson J, Shivappa N, Hebert JR, Nilsson LM. Dietary inflammatory index and risk of first myocardial infarction; a prospective population-based study. Nutr J. 2017;16:21.

204. Sui Y-H, Luo W-J, Xu Q-Y, Hua J. Dietary saturated fatty acid and polyunsaturated fatty acid oppositely affect hepatic NOD-like receptor protein 3 inflammasome through regulating nuclear factor-kappa B activation. World J Gastroenterol. 2016;22:2533.

205. Lumeng CN, DeYoung SM, Bodzin JL, Saltiel AR. Increased Inflammatory Properties of Adipose Tissue Macrophages Recruited During Diet-Induced Obesity. Diabetes. 2007;56:16-23.

206. Kim K-A, Gu W, Lee I-A, Joh E-H, Kim D-H. High Fat Diet-Induced Gut Microbiota Exacerbates Inflammation and Obesity in Mice via the TLR4 Signaling Pathway. PLOS ONE. 2012;7:e47713.

207. Eichelmann F, Schwingshackl L, Fedirko V, Aleksandrova K. Effect of plant-based diets on obesity-related inflammatory profiles: a systematic review and meta-analysis of intervention trials. Obes Rev. 2016;17:1067-79.

208. Altunoğlu E, Müderrisoğlu C, Erdenen F, Ülgen E, Ar MC. The Impact of Obesity and Insulin Resistance on Iron and Red Blood Cell Parameters: A Single Center, CrossSectional Study. Turk J Hematol. 2014;31:61-7. 
209. Chang J-S, Chen Y-C, Owaga E, Palupi KC, Pan W-H, Bai C-H. Interactive Effects of Dietary Fat/Carbohydrate Ratio and Body Mass Index on Iron Deficiency Anemia among Taiwanese Women. Nutrients. 2014;6:3929-41.

210. Cheng HL, Bryant CE, Rooney KB, Steinbeck KS, Griffin HJ, Petocz P, O’Connor HT. Iron, Hepcidin and Inflammatory Status of Young Healthy Overweight and Obese Women in Australia. PLOS ONE. 2013;8:e68675.

211. Gruys E, Toussaint MJM, Niewold TA, Koopmans SJ. Acute phase reaction and acute phase proteins. J Zhejiang Univ Sci B. 2005;6:1045-56.

212. Ritchie RF, Palomaki GE, Neveux LM, Navolotskaia O. Reference distributions for the negative acute-phase proteins, albumin, transferrin, and transthyretin: a comparison of a large cohort to the world's literature. J Clin Lab Anal. 1999;13:280-6.

213. Charlie-Silva I, Klein A, Gomes JMM, Prado EJR, Moraes AC, Eto SF, Fernandes DC, Fagliari JJ, Junior JDC, Lima C, et al. Acute-phase proteins during inflammatory reaction by bacterial infection: Fish-model. Sci Rep. 2019;9:4776.

214. Zhao H-Q, Wu H, Meng R, Du S, Tao S-J. Distribution of serum transferrin, and its associations with metabolic disorders among Chinese: A nation-wide, health and nutrition survey. Mol Nutr Food Res. 2015;59:1535-40.

215. Abo Zeid AA, El Saka MH, Abdalfattah AA, Zineldeen DH. Potential factors contributing to poor iron status with obesity. Alex J Med. 2014;50:45-8. 